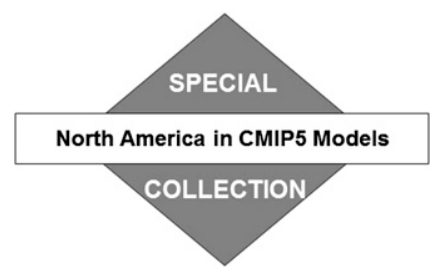

\title{
CMIP5 Projected Changes in the Annual Cycle of Precipitation in Monsoon Regions
}

\author{
ANJI SETH \\ Department of Geography, University of Connecticut, Storrs, Connecticut \\ SARA A. RAUSCHER \\ Los Alamos National Laboratory, Los Alamos, New Mexico \\ Michela Biasutti, Alessandra Giannini, and Suzana J. CAMargo \\ Columbia University, New York, New York \\ MAISA ROJAS \\ University of Chile, Santiago, Chile
}

(Manuscript received 3 October 2012, in final form 27 February 2013)

\begin{abstract}
Analyses of phase 5 of the Coupled Model Intercomparison Project (CMIP5) experiments show that the global monsoon is expected to increase in area, precipitation, and intensity as the climate system responds to anthropogenic forcing. Concurrently, detailed analyses for several individual monsoons indicate a redistribution of rainfall from early to late in the rainy season. This analysis examines CMIP5 projected changes in the annual cycle of precipitation in monsoon regions, using a moist static energy framework to evaluate competing mechanisms identified to be important in precipitation changes over land. In the presence of sufficient surface moisture, the local response to the increase in downwelling energy is characterized by increased evaporation, increased low-level moist static energy, and decreased stability with consequent increases in precipitation. A remote mechanism begins with warmer oceans and operates on land regions via a warmer tropical troposphere, increased stability, and decreased precipitation. The remote mechanism controls the projected changes during winter, and the local mechanism controls the switch to increased precipitation during summer in most monsoon regions. During the early summer transition, regions where boundary layer moisture availability is reduced owing to decreases in evaporation and moisture convergence experience an enhanced convective barrier. Regions characterized by adequate evaporation and moisture convergence do not experience reductions in early summer precipitation.

This enhanced convective barrier leads to a redistribution of rainfall from early to late summer, and is robust in the American and African monsoons but muddled in Asia. As described here, viewing monsoons from their inherent ties to the annual cycle could help to fingerprint changes as they evolve.
\end{abstract}

\section{Introduction}

Under increasing greenhouse gas concentrations, landsea thermal contrasts are expected to increase. The increase is in part due to differences in thermal inertia

Corresponding author address: Anji Seth, Department of Geography, University of Connecticut, U-4148 215 Glenbrook Rd., Storrs, CT 06269.

E-mail: anji.seth@uconn.edu between land and ocean but largely because oceans divert more of the anomalous incoming energy into latent heat rather than increasing surface temperature (Sutton et al. 2007). Where moisture is abundant (i.e., over oceans), warmer surface temperatures lead to robust increases in atmospheric water vapor owing to the nonlinear ClausiusClapeyron relationship, which are associated with weakening of the tropical (Hadley, Walker, and monsoon) circulations (Held and Soden 2006). Over land, warmer temperatures are accompanied by decreases in relative 
humidity and a higher lifting condensation level (Fasullo 2012). The response of global monsoons to greenhouse warming is thus complicated by a number of factors, including the dynamical weakening of the tropical circulation (Tanaka et al. 2005; Vecchi and Soden 2007), related changes in the tropical tropospheric stability (Chou et al. 2001; Neelin et al. 2003), and the regional effects of aerosols and black carbon (Lau et al. 2006; Meehl et al. 2008).

Despite the weakening of tropical circulations, the World Climate Research Programme (WCRP) phase 3 of the Coupled Model Intercomparison Project (CMIP3) multimodel climate projections suggested a tendency toward increased monsoon precipitation and increased low-level moisture convergence (Christensen et al. 2007). These results have recently been reaffirmed by analysis of a CMIP5 suite of experiments, which indicate increases in the global monsoon (Trenberth et al. 2000; Wang et al. 2012) precipitation, intensity, and area (including land and oceans) (Lee and Wang 2012; Hsu et al. 2012, 2013; Kitoh et al. 2013). The overall strengthening of the global monsoon results largely from the thermodynamic effect of increased atmospheric water vapor. Regionally, CMIP3 projections suggest precipitation increases in Australia (Meehl et al. 2007) and South Asia (Douville et al. 2000). In South Asia a 5\%-25\% increase in precipitation was found in the models that best represented the interannual variability and teleconnections associated with the monsoon (Annamalai et al. 2007). However, the North American monsoon region is expected to become drier in the annual mean (Seager et al. 2007), and much uncertainty was seen in projections of the West African and South American monsoons (e.g., Giannini et al. 2008; Vera et al. 2006).

Most previous studies have focused on the fully established wet and dry seasons (December-February and June-August). However, studies that examine the full annual cycle indicate a redistribution of precipitation within the rainy season. For example, the South American and West African monsoons both exhibit drying in spring and increased precipitation during summer in projections (Seth et al. 2009; Biasutti and Sobel 2009; Biasutti et al. 2009; Biasutti 2013). Despite the disagreement among climate models regarding projections of annual or warm season mean Sahel precipitation in the twenty-first century (e.g., Giannini et al. 2008), there is near consensus regarding a weakening of early and strengthening of late season rainfall (Biasutti and Sobel 2009; Biasutti 2013). Models indicate a similar reduction in spring and an increase in summer precipitation in the core region of the South American monsoon, which is associated with insufficient low-level moisture convergence in spring and a substantial increase in convergence during summer (Seth et al. 2009).
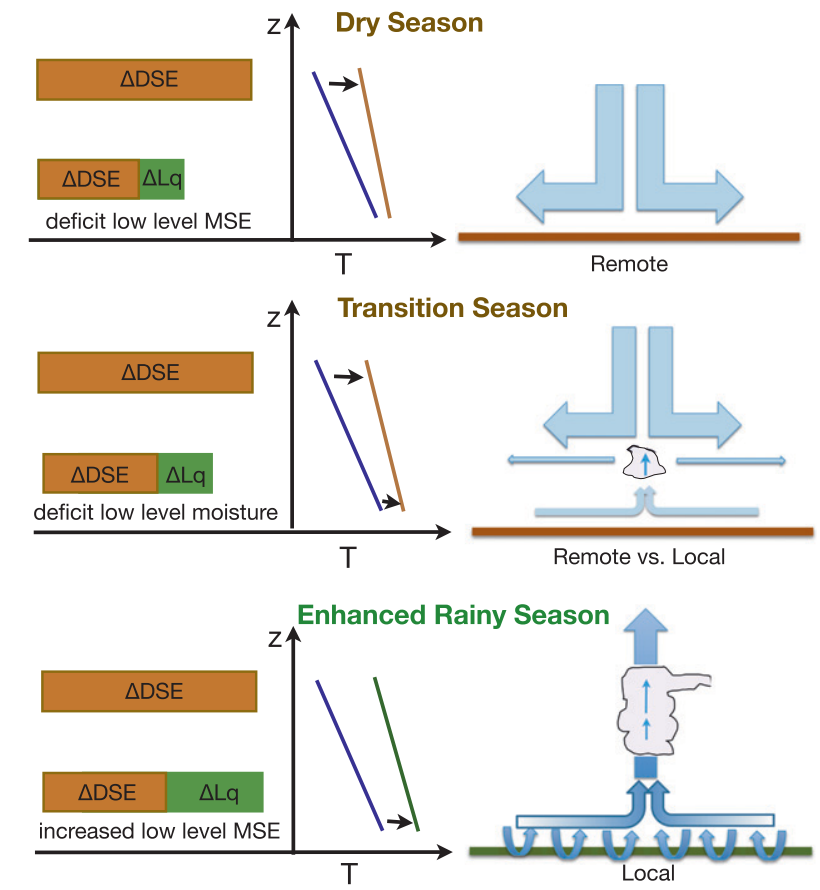

FIG. 1. Schematic representation of changes in the tropical troposphere and effects of remote and local mechanisms: $Z$ indicates height above the surface and $T$ air temperature. A change in the lapse rate is given by status quo vertical profile (blue) and projected change (brown or green). In all seasons the temperature increase in the upper troposphere results in increased DSE. Nearer the surface, the change in MSE is small during the dry season and large in the wet season. During the transition, increases in surface MSE are dominated by increasing temperature.

Our study of monsoons based on CMIP3 data found a redistribution of precipitation from early to late summer in five of seven monsoon regions globally (Seth et al. 2011, hereafter SRRGC). The analysis of twentieth century (20C) and Special Report on Emissions Scenarios (SRES) A2 scenario experiments employed a moist static energy (MSE) framework, which exploits the role of evaporation in both energy and water budgets (Neelin and Held 1987). Based on Giannini (2010), two competing mechanisms were examined, involving the differing responses of simulated precipitation to greenhouse gas forcing: remote (or top down) and local (or bottom up). A schematic of these mechanisms is provided in Fig. 1. In the remote mechanism, SST warming leads to large-scale tropospheric warming, enhances vertical stability in the global tropics (Sobel et al. 2002; Chiang and Sobel 2002), and reduces continental precipitation in those regions that cannot meet the increasing demand for near-surface moist static energy (Chou et al. 2001; Neelin et al. 2003). In this case, the precipitation reduction is reinforced by a consequent reduction in evaporation owing to decreased precipitation 
recycling. In the second, local mechanism, the land surface response to anthropogenically enhanced terrestrial radiative forcing dominates. Where surface moisture is sufficient, increased downwelling longwave radiation causes increased evaporation, which leads to near-surface increases in moist static energy, instability, and precipitation. The increase in precipitation is then reinforced by enhanced moisture convergence. Where moisture is insufficient, increased terrestrial radiation is balanced by increased sensible heat flux. In our CMIP3 analysis, the remote mechanism dominates during the dry season and the local mechanism dominates during the rainy season. During the transition from dry to wet (i.e., in spring), SRRGC suggested that insufficient moisture availability at the end of an intensified dry season would favor an extension of the top-down mechanism and delay hand off to bottom-up destabilization, resulting in diminished early season rainfall.

Low latitudes are characterized by relatively short decay time scales for soil moisture owing to high net radiation; therefore, evaporation rates are moisture limited (Delworth and Manabe 1988). In monsoon regions, soil moisture has potential to influence atmospheric variability in early summer as net radiation and potential evaporation increase but before soil saturation occurs (Delworth and Manabe 1989). Indeed, analysis of CMIP5 projections indicates that future reductions in latent heat fluxes result from decreases in surface wetness in low latitudes (Dirmeyer et al. 2013). Fasullo (2012) suggested that increased low-level moisture convergence was required to sustain summertime rainfall in monsoon regions, as surface temperatures increase and near-surface relative humidity decreases over land.

Possible causes for these changes in the global tropical annual cycle are also being investigated. Dwyer et al. (2012) have examined the possible connections between a projected delay in high-latitude SST, which results from reductions in sea ice, and the delay in the tropical precipitation annual cycle. While high-latitude SST changes were found unlikely to be the cause, increases in the amplitude of the annual cycle of low-latitude SST could play a role in delaying monsoon precipitation (J. G. Dwyer 2013, personal communication). An alternative possibility is that a poleward shift in midlatitude storm tracks is responsible for the springtime weakening of rainfall in the subtropics (Scheff and Frierson 2012a,b), which could affect the northern margins of the North American monsoon region.

In the present study a new suite of experiments from the WCRP Coupled Model Intercomparison Project (CMIP5) archive (Taylor et al. 2012) is analyzed to further explore the response of precipitation in monsoon regions to radiative forcings in the twenty-first century. The analysis is extended beyond that of SRRGC to evaluate the role of moisture flux divergence changes in delaying the activation of the local mechanism in spring. This analysis is performed through the annual cycle, thus permitting a view of both transition seasons. We show that, despite model uncertainties, a redistribution of precipitation in the annual cycle is discernible in the CMIP5 projections and is part of a global response to greenhouse forcing. However, there are notable changes from the CMIP3 results. The remainder of this paper is structured as follows: the coupled climate models, experiments, and observations employed in this research are described in section 2. In section 3, results are presented from the CMIP5 database for present day and future periods using the historical and representative concentration pathways RCP8.5 experiments. Discussion of results and analysis of additional experiments are provided in section 4 , with a summary and conclusions in section 5 .

\section{Methods}

This analysis employs multimodel ensemble experiments from the WCRP CMIP5 dataset (Taylor et al. 2012). Historical simulations (hereafter Hist) are analyzed and compared with observed estimates from the Climate Prediction Center (CPC) Merged Analysis of Precipitation (CMAP) version 2 (Xie and Arkin 1996), which employs satellite and gauge data in a globally gridded product for the recent period (1981-2005).

The twenty-first-century experiments in CMIP5 are based on representative concentration pathways (RCPs) (van Vuuren et al. 2011). We analyze the higher concentration scenario in which the net radiative forcing in the year 2100 is $8.5 \mathrm{~W} \mathrm{~m}^{-2}$ and focus on 30 -yr periods for the historical (Hist, 1971-2000) and late twenty-first century (RCP8.5, 2071-2100). Note that the RCP8.5 scenario yields a larger global-mean temperature response $\left(+0.7^{\circ} \mathrm{C}\right)$ compared to the SRES A2 scenario CMIP3 results (Rogelj et al. 2012). In addition, the CMIP5 models have different implementations of the effects of short-lived radiatively active trace gases and aerosols (Lamarque et al. 2011), which further complicate comparisons between CMIP3 and CMIP5 results. Seventeen models, identified in Table 1, constitute the ensemble from which monthly precipitation, moist static energy, divergence, and evaporation are examined for the Hist and RCP8.5 experiments. While the coupled models include relatively sophisticated treatments of land surface processes, they vary in substantive ways the processes included and in the details and levels of complexity of implementation. At least two models now incorporate subgrid-scale hydrology (Gedney and Cox 
TABLE 1. CMIP5 coupled models analyzed in this study using the Hist and RCP8.5 experiments. Atmosphere resolution is shown as the number of grids in latitude $\times$ longitude. A single realization, as specified, is employed for each model.

\begin{tabular}{|c|c|c|c|c|}
\hline Institution & Model acronym & Model & Realization & $\begin{array}{l}\text { Atmosphere } \\
\text { resolution }\end{array}$ \\
\hline $\begin{array}{l}\text { National Center for Atmospheric } \\
\text { Research (NCAR) }\end{array}$ & CCSM4 & $\begin{array}{l}\text { Community Climate System Model, } \\
\text { version } 4\end{array}$ & r1i1p1 & $192 \times 288$ \\
\hline $\begin{array}{l}\text { Centre Européen de Recherche et de } \\
\text { Formation Avancée en Calcul } \\
\text { Scientifique (CERFACS) }\end{array}$ & CNRM-CM5 & $\begin{array}{l}\text { Centre National de Recherches } \\
\text { Météorologiques Coupled Global } \\
\text { Climate Model, version } 5\end{array}$ & r2i1p1 & $128 \times 256$ \\
\hline $\begin{array}{l}\text { Commonwealth Scientific and } \\
\text { Industrial Research Organisation } \\
\text { Bureau of Meteorology } \\
\text { (CSIRO-BOM) }\end{array}$ & CSIRO Mk3.6.0* & $\begin{array}{l}\text { Commonwealth Scientific and } \\
\text { Industrial Research Organisation } \\
\text { Mark, version 3.6.0 }\end{array}$ & r1i1p1 & $96 \times 192$ \\
\hline $\begin{array}{l}\text { Canadian Centre for Climate } \\
\text { Modelling and Analysis (CCCma) }\end{array}$ & CanESM2* & $\begin{array}{l}\text { Second Generation Canadian Earth } \\
\text { System Model }\end{array}$ & r1i1p1 & $64 \times 128$ \\
\hline First Institute of Oceanography (FIO) & FIO-ESM & $\begin{array}{l}\text { First Institute of Oceanography Earth } \\
\text { System Model }\end{array}$ & r1i1p1 & $64 \times 128$ \\
\hline $\begin{array}{l}\text { National Oceanic and Atmospheric } \\
\text { Administration (NOAA)/ } \\
\text { Geophysical Fluid Dynamics } \\
\text { Laboratory (GFDL) }\end{array}$ & GFDL CM3 & $\begin{array}{l}\text { Geophysical Fluid Dynamics Laboratory } \\
\text { Climate Model, version } 3\end{array}$ & r1i1p1 & $90 \times 144$ \\
\hline NOAA/GFDL & GFDL-ESM2M* & $\begin{array}{l}\text { Geophysical Fluid Dynamics Laboratory } \\
\text { Earth System Model with Modular Ocean } \\
\text { Model } 4 \text { (MOM4) component (ESM2M) }\end{array}$ & r1i1p1 & $90 \times 144$ \\
\hline $\begin{array}{l}\text { National Aeronautics and Space } \\
\text { Administration (NASA) Goddard } \\
\text { Institute for Space Studies (GISS) }\end{array}$ & GISS-E2-R & $\begin{array}{l}\text { Goddard Institute for Space Studies Model E, } \\
\text { coupled with the Russell ocean model }\end{array}$ & r1i1p1 & $90 \times 144$ \\
\hline $\begin{array}{l}\text { Met Office (UKMO) Hadley } \\
\text { Centre for Climate Change }\end{array}$ & HadGEM2* & $\begin{array}{l}\text { Hadley Centre Global Environment Model, } \\
\text { version } 2\end{array}$ & r1i1p1 & $144 \times 192$ \\
\hline $\begin{array}{l}\text { L'Institut Pierre-Simon } \\
\text { Laplace (IPSL) }\end{array}$ & IPSL-CM5A-LR* & $\begin{array}{l}\text { L'Institut Pierre-Simon Laplace Coupled } \\
\text { Model, version 5, coupled with NEMO, } \\
\text { low resolution }\end{array}$ & r1i1p1 & $96 \times 96$ \\
\hline IPSL & IPSL-CM5A-MR* & $\begin{array}{l}\text { L'Institut Pierre-Simon Laplace Coupled } \\
\text { Model, version 5, coupled with } \\
\text { NEMO, mid resolution }\end{array}$ & r1i1p1 & $143 \times 144$ \\
\hline $\begin{array}{l}\text { Model for Interdisciplinary } \\
\text { Research on Climate (MIROC) }\end{array}$ & MIROC-ESM* & $\begin{array}{l}\text { Model for Interdisciplinary Research on } \\
\text { Climate, Earth System Model }\end{array}$ & r1i1p1 & $64 \times 128$ \\
\hline MIROC & MIROC5* & $\begin{array}{l}\text { Model for Interdisciplinary Research on } \\
\text { Climate, version } 5\end{array}$ & r1i1p1 & $128 \times 256$ \\
\hline $\begin{array}{l}\text { Max Planck Institute for } \\
\text { Meteorology (MPI-M) }\end{array}$ & MPI-ESM-LR* & $\begin{array}{l}\text { Max Planck Institute Earth System Model, } \\
\text { low resolution }\end{array}$ & r1i1p1 & $96 \times 192$ \\
\hline $\begin{array}{l}\text { Meteorological Research } \\
\text { Institute (MRI) }\end{array}$ & MRI-CGCM3 & $\begin{array}{l}\text { Meteorological Research Institute Coupled } \\
\text { Atmosphere-Ocean General Circulation } \\
\text { Model, version } 3\end{array}$ & r1i1p1 & $160 \times 320$ \\
\hline Norwegian Climate Centre (NCC) & NorESM1* & $\begin{array}{l}\text { Norwegian Earth System Model, } \\
\text { version } 1 \text { (intermediate resolution) }\end{array}$ & r1i1p1 & $96 \times 144$ \\
\hline $\begin{array}{l}\text { Institute of Numerical } \\
\text { Mathematics (INM) }\end{array}$ & INM-CM4.0* & $\begin{array}{l}\text { Institute of Numerical Mathematics } \\
\text { Coupled Model, version } 4.0\end{array}$ & r1i1p1 & $120 \times 180$ \\
\hline
\end{tabular}

* Models for which the preindustrial control and $1 \% \mathrm{CO}_{2}$ experiments are employed.

2003; Oleson et al. 2008; Lawrence et al. 2011), and many include river networking to route runoff to appropriate ocean basins (e.g., Oki et al. 1999). Fifty years from the preindustrial control (piCont, years 151-200) and the transient $1 \% \mathrm{CO}_{2}\left(1 \% \mathrm{CO}_{2}\right.$, years $\left.91-140\right)$ are examined in order to isolate and simplify the climate response to greenhouse gas radiative forcing. Data from the piCont and $1 \% \mathrm{CO}_{2}$ experiments are limited to an 11-model subset (identified by asterisks in Table 1).
While comparison with the CMIP3 results of SRRGC cannot be made directly due to the many differences in the models and scenarios, the monsoon regions are defined similarly for some degree of consistency, as follows: North America (NAM: $115^{\circ}-102.5^{\circ} \mathrm{W}, 20^{\circ}-35^{\circ} \mathrm{N}$ ), South America (SAM: $60^{\circ}-40^{\circ} \mathrm{W}, 10^{\circ}-25^{\circ} \mathrm{S}$ ), West Africa (WAf: $10^{\circ} \mathrm{W}-10^{\circ} \mathrm{E}, 10^{\circ}-25^{\circ} \mathrm{N}$ ), Southern Africa (SAf: $20^{\circ}-40^{\circ} \mathrm{E}, 10^{\circ}-25^{\circ} \mathrm{S}$ ); South Asia (SAsia: $65^{\circ}-85^{\circ} \mathrm{E}, 10^{\circ}-$ $25^{\circ} \mathrm{N}$ ), Southeast Asia (SEA: $100^{\circ}-120^{\circ} \mathrm{E}, 10^{\circ}-25^{\circ} \mathrm{N}$ ), and 
Australia (Aus: $130^{\circ}-150^{\circ} \mathrm{E}, 10^{\circ}-25^{\circ} \mathrm{S}$ ). These regions are identified as boxes on the map in Fig. 3, but only land points are used in the regional analyses. Note, however, that most of the analyses presented here employ Hovmöller plots that show the latitudinal extent of the monthly evolution of various fields. Only the bar chart in Fig. 2 utilizes area averages performed over the specified boxes. Precipitation results are shown as percent differences to allow for comparison with SRRGC where possible. However, in the moisture budget discussion all variables are shown in millimeters per day. All model data have been regridded to the $64 \times 128$ (T42) resolution.

\section{Evaluation of simulated annual cycle}

Since the CMIP5 dataset is new, the multimodel ensemble precipitation annual cycle is briefly evaluated. The observed (CMAP) annual cycle is shown (black contours with thicker contours beginning at $5 \mathrm{~mm} \mathrm{day}^{-1}$ ) as a latitude versus time Hovmöller plot of the zonalmean averaged precipitation in Fig. 2 for the globe with land and ocean in Fig. 2a and land only in Fig. 2b. Individual monsoon regions are shown in Figs. 2c-i. The latitude axis provides a view of the poleward migration of rainfall during the warm season. The multimodel ensemblemean bias (difference from CMAP) is shown in color.

The monsoons in the Northern Hemisphere exhibit peak rainfall and poleward extension in July and August and those in the Southern Hemisphere during January and February. The global view of the model precipitation error indicates that the models are wetter than the observed estimates for the Southern Hemisphere monsoons and show a dry bias in June-August (JJA) in the monsoon core. It is clear that the CMIP5 suite of models still has problems representing the regional monsoon rainfall: the models are drier than observed in the early rainy seasons of South America and South Asia and wetter in the late rainy season. Through much of the rainy seasons in Southeast Asia and Australia equatorward of $20^{\circ}$ latitude they are also too dry. The precipitation in West Africa is overestimated, except in July and August on the northern margin of the monsoon, where the models exhibit a modest dry bias. In North America and Southern Africa the models overestimate rainfall. Although early summer dry biases are evident in several regions, the structure of the errors by latitude and month appears to be unique to each region without consistency between regions. Results from analysis of projections will be considered in the context of these model errors in section 4 .

\section{Results}

In this section the following questions are posed: 1) Do the CMIP5 models show a response in the annual cycle similar to CMIP3? Given the stronger radiative forcing in RCP8.5 compared to that in SRES A2, the expectation would be for a similar, if not stronger, response. 2) If the CMIP5 models show a redistribution from early to late summer, is the response embedded in a coherent globalscale change in the annual cycle? 3) Why do the regional monsoons respond as they do? Does the mechanism suggested by SRRGC hold in these new results, and what role is played by moisture transport?

The projected regional precipitation changes are presented in Fig. 3, which shows a map of the early summer (June/November) ensemble mean percent differences in the Northern/Southern Hemisphere. Also shown are precipitation differences $\left(\mathrm{mm} \mathrm{day}^{-1}\right.$, masked for areas with $<0.5 \mathrm{~mm} \mathrm{day}^{-1}$ ) in bar plots for each region, with individual model responses shown by month in the annual cycle. This map illustrates the global scale of the spring response, with decreases in rainfall projected throughout most of the subtropics $\left(10^{\circ}-30^{\circ}\right.$ poleward of the equator), with the exception of Asia and the west Pacific. The bar plots provide an indication of the agreement among the models regarding the sign and magnitude of precipitation change by month in the monsoon regions. For the American and African monsoons, while the average of the rainy season may show little or no change in precipitation (and model disagreement on the sign of the change), a view of changes in the annual cycle presents a stronger model agreement in reduction of early and increase in late season rainfall. Because the boxes defined for North America and West Africa extend farther poleward than those regions defined as part of the global monsoon, the area averaged precipitation differences were computed for regions limited to a lower latitude $\left(20^{\circ}-30^{\circ} \mathrm{N}\right.$ for North America and $10^{\circ}-20^{\circ} \mathrm{N}$ for West Africa). The latitude-limited regions yield in a stronger agreement among the models regarding the shift from early to late season rainfall. The models also agree regarding the projected precipitation increases in the South and Southeast Asian monsoons. The Australian monsoon precipitation response remains uncertain through most of the annual cycle.

\section{a. Global-scale changes in the tropical annual cycle}

In the CMIP3 projections of future climate change under a high greenhouse gas forcing scenario (A2), a robust large-scale signal emerged in tropical and subtropical precipitation. Summer hemisphere wet seasons and winter hemisphere dry seasons simultaneously strengthened, creating an asymmetric interhemispheric response (Tan et al. 2008), with impacts in various characteristics of the summer tropical climate response (Sobel and Camargo 2010). In the global monsoon, this shift was visible as an extension of the dry season into 

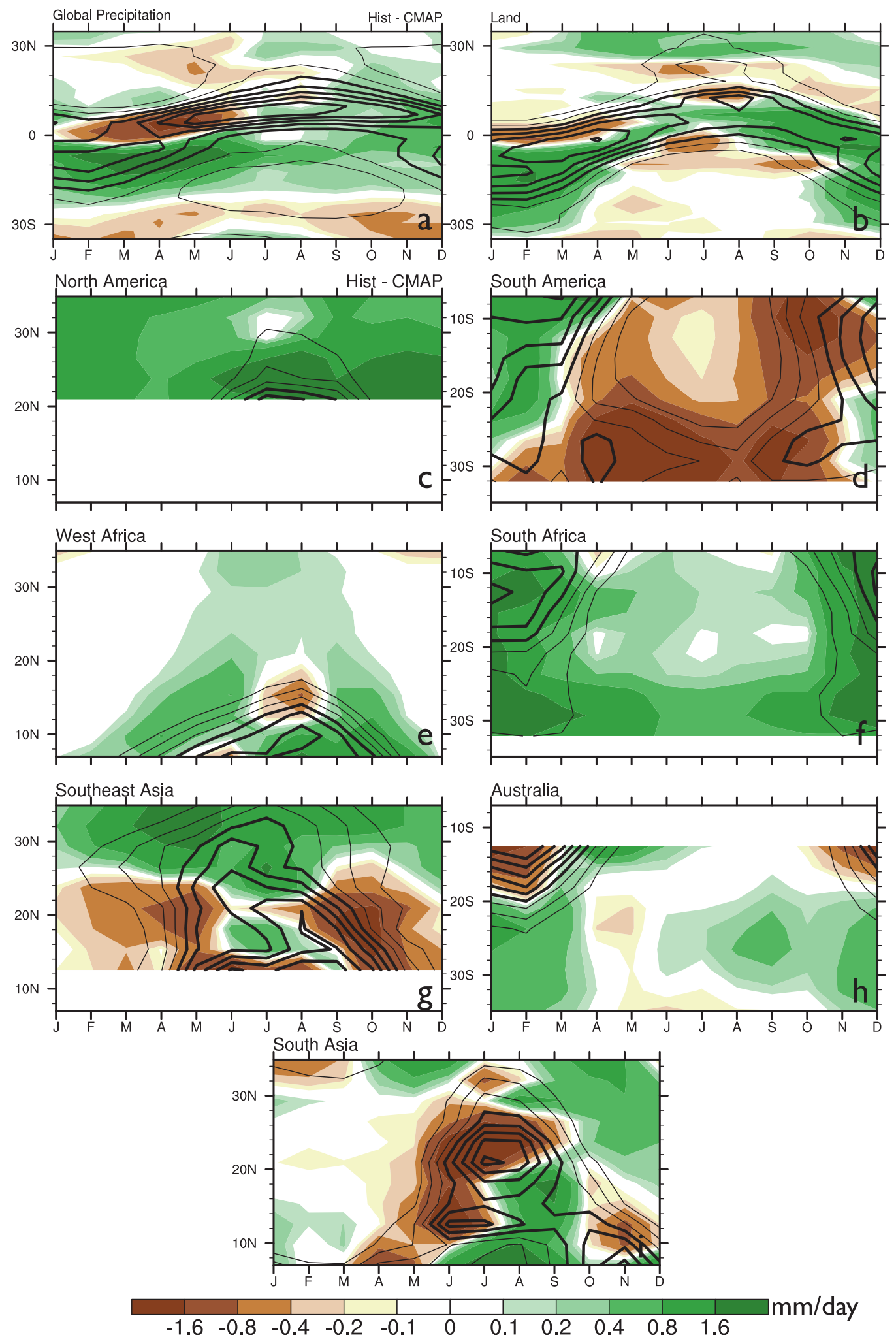

FIG. 2. Annual cycles of regional monsoon precipitation, averaged (a) for longitudes globally, (b) for land only, and (c)-(i) as specified in text for each region, from CMAP observed estimate (black contours 2-10 with interval 1; thicker lines begin at $5 \mathrm{~mm} \mathrm{day}^{-1}$ ) and differences between the CMIP5 17-model ensemble mean Hist minus CMAP (colors, $\mathrm{mm} \mathrm{day}^{-1}$ ) for the period 1981-2005. 

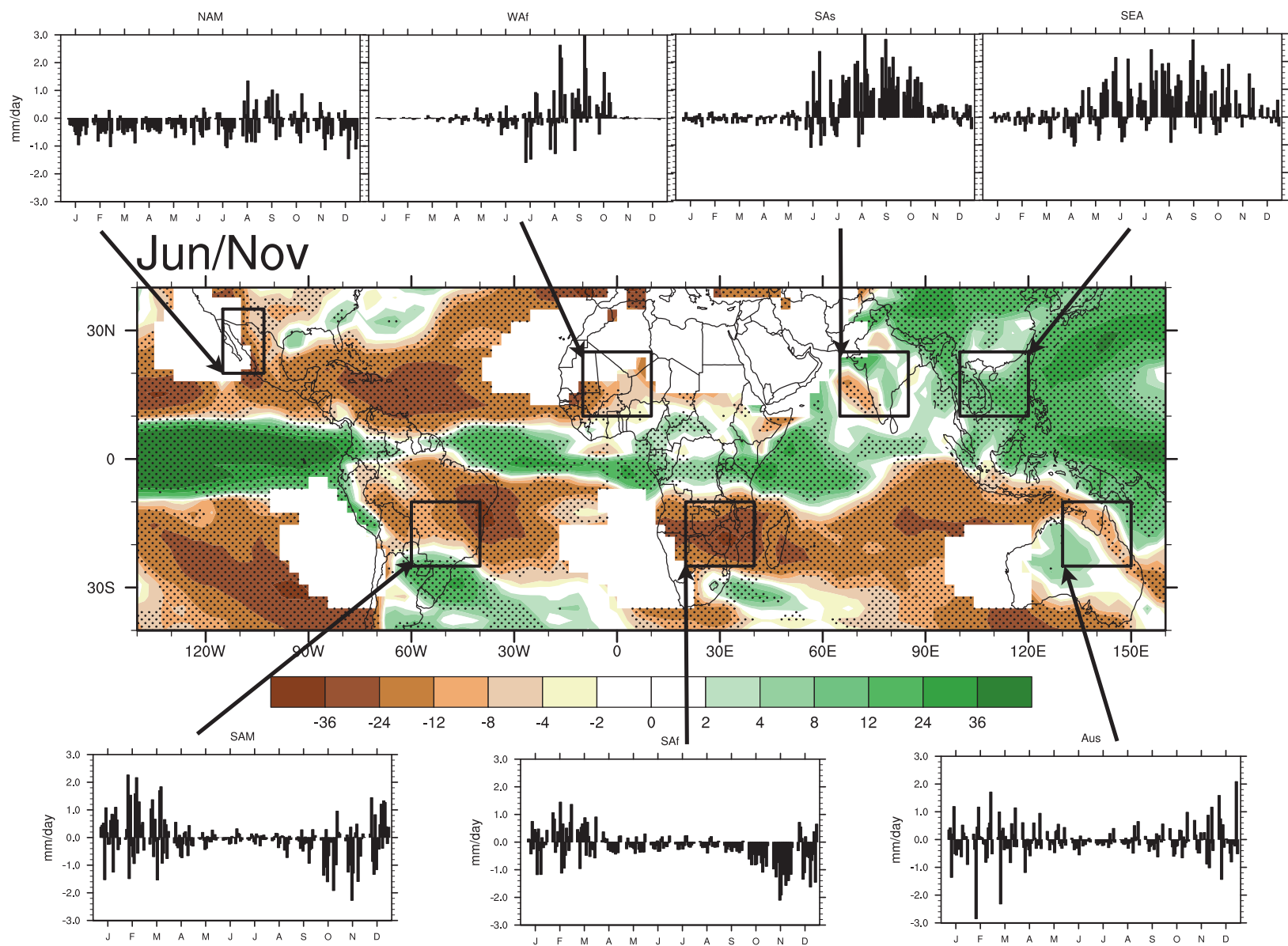

FIG. 3. Precipitation percent difference (colors) between the 17-model ensemble-mean RCP8.5 minus Hist, masked for areas where climatological precipitation is less than $0.5 \mathrm{~mm} \mathrm{day}^{-1}$. Map shows June for the Northern Hemisphere and November for the equator and Southern Hemisphere. Stippling indicates significance at the $1 \%$ level. Individual model monthly precipitation differences $\left(\mathrm{mm}^{-1 a y}{ }^{-1}\right.$, RCP8.5-Hist) are given in bar charts for each region as specified in the map.

spring and an enhancement of late summer precipitation (see Figs. 2a,b in SRRGC). Here we see a similar response in the CMIP5 models, as shown in Figs. 4a,b, which present the annual cycle of zonal mean precipitation in the tropics (land and ocean) for the historical experiments (black contours, with thicker contours beginning at $5 \mathrm{~mm} \mathrm{day}^{-1}$ ) and changes in the RCP8.5 scenario (color shading). The global precipitation annual cycle shows the tropical rainfall band migrating poleward in the summer hemisphere [December-February (DJF) in the Southern; JJA in the Northern]. The intensification of both wet and dry seasons is apparent in the projected changes (colors). During the transition from the dry to wet season, there is a reduction of precipitation (Fig. 4a). This suggests that, for the global monsoon, there is a redistribution of precipitation from early to late rainy season.

In the Northern Hemisphere, the springtime precipitation reduction is weaker over land than in the global mean (Fig. 4b), but the opposite is true for the Southern Hemisphere. The late rainy seasons (FebruaryMarch and August-September) show clear strengthening of summer rainfall over land in both hemispheres. The Northern Hemisphere response over land is weaker in CMIP5 than in CMIP3. This weaker Northern Hemisphere response will be examined further in section 4 through the use of the $\mathrm{CO}_{2}$-only experiments.

The remote and local mechanisms are examined in terms of changes in the gross stability of the tropical troposphere, estimated by the vertical gradient of moist static energy $(\mathrm{MSE}=\mathrm{DSE}+L q)$. The dry static energy is defined as DSE $=c_{p} T+g Z$, where $c_{p}$ is the specific heat at constant pressure, $T$ is the layer temperature, $g$ is gravity, $Z$ is the geopotential height, $L$ is the latent heat of evaporation, and $q$ is the specific humidity. As a measure of the free-tropospheric stability, we examine changes in the vertical gradient of moist static energy $\nabla M S E$, which is approximated by $\nabla M S E=M_{200}-M_{S E} E_{850}$. 

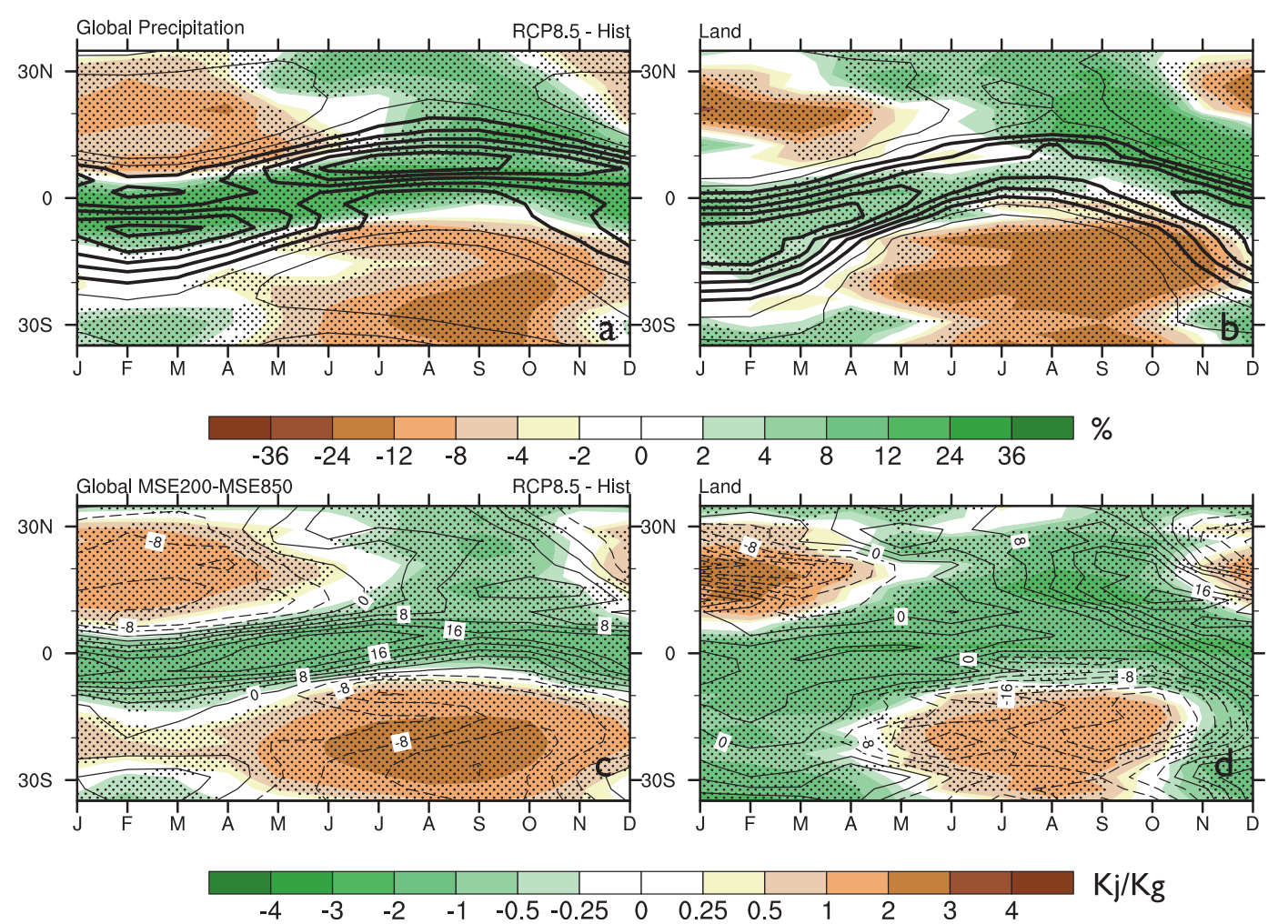

FIG. 4. The 17-model ensemble mean annual cycles of (a),(b) global tropical precipitation percentage differences for RCP8.5 minus Hist (colors) with climatological precipitation for Hist (black contours, 2-10 with interval 1, thicker lines begin at $5 \mathrm{~mm} \mathrm{day}{ }^{-1}$ ) and (c),(d) $\nabla \mathrm{MSE}\left(\mathrm{kJ} \mathrm{kg}^{-1}\right)$ differences (colors) and precipitation percentage differences (black contours, dashed lines for values less than zero) averaged (left) for all longitudes and (right) for land only. Stippling indicates significance at the $1 \%$ level.

The annual cycle for $\mathrm{DMSE}$ is presented in the zonal mean (Fig. 4c) and for land only (Fig. 4d). Positive (negative) changes in $\nabla$ MSE indicate greater stability (instability), which would tend to inhibit (enhance) precipitation in future projections. Precipitation percentage differences (RCP8.5 - Hist) are also shown in Figs. 4c,d as black contours. Changes in tropospheric stability are not consistent throughout the year in the subtropics. In winter, the $\nabla$ MSE increases, indicating greater stability to convection and, in summer, it becomes more negative (i.e., less stable). Figure $4 \mathrm{~d}$ also shows that, during the spring transition from dry to wet seasons (AugustOctober and March-May), the increase in VMSE persists, indicating increased stability to convection over land. Therefore, the projected springtime drying is controlled at least in part by the remote (top down) mechanism.

If we examine Fig. $4 \mathrm{~d}$ closely, the wintertime decrease in precipitation continues into November (Southern Hemisphere spring), even after VMSE indicates a transition from a more stable to a less stable troposphere. The extension of the drying into early summer was examined in SRRGC by separating VMSE into its temperature and moisture terms, and it was shown that the early summer increase in low-level moist static energy resulted from the temperature term. Only after the moisture term increased in early summer did the precipitation change reverse from drier to wetter conditions. In the CMIP5 simulations, similar changes in temperature and moisture terms occur over the Southern Hemisphere (not shown). However, again the Northern Hemisphere response in the CMIP5 models differs from CMIP3. The lag between the decrease in DMSE and the increase in precipitation in the Northern Hemisphere is smaller, or even arguably absent, in CMIP5 compared to CMIP3. We will investigate further the Northern Hemisphere reduction in the global signal of springtime drying over land by examining additional experiments in section 4 . The next question is what is the regional response in each monsoon?

\section{b. Annual cycle changes in monsoon regions}

To analyze the regional monsoon responses, the CMIP5 ensemble-mean changes in the annual cycles of precipitation averaged over longitudes of each monsoon region are shown in Fig. 5 (see section 2 for region definitions, which are shown in Fig. 3). Here the regional 

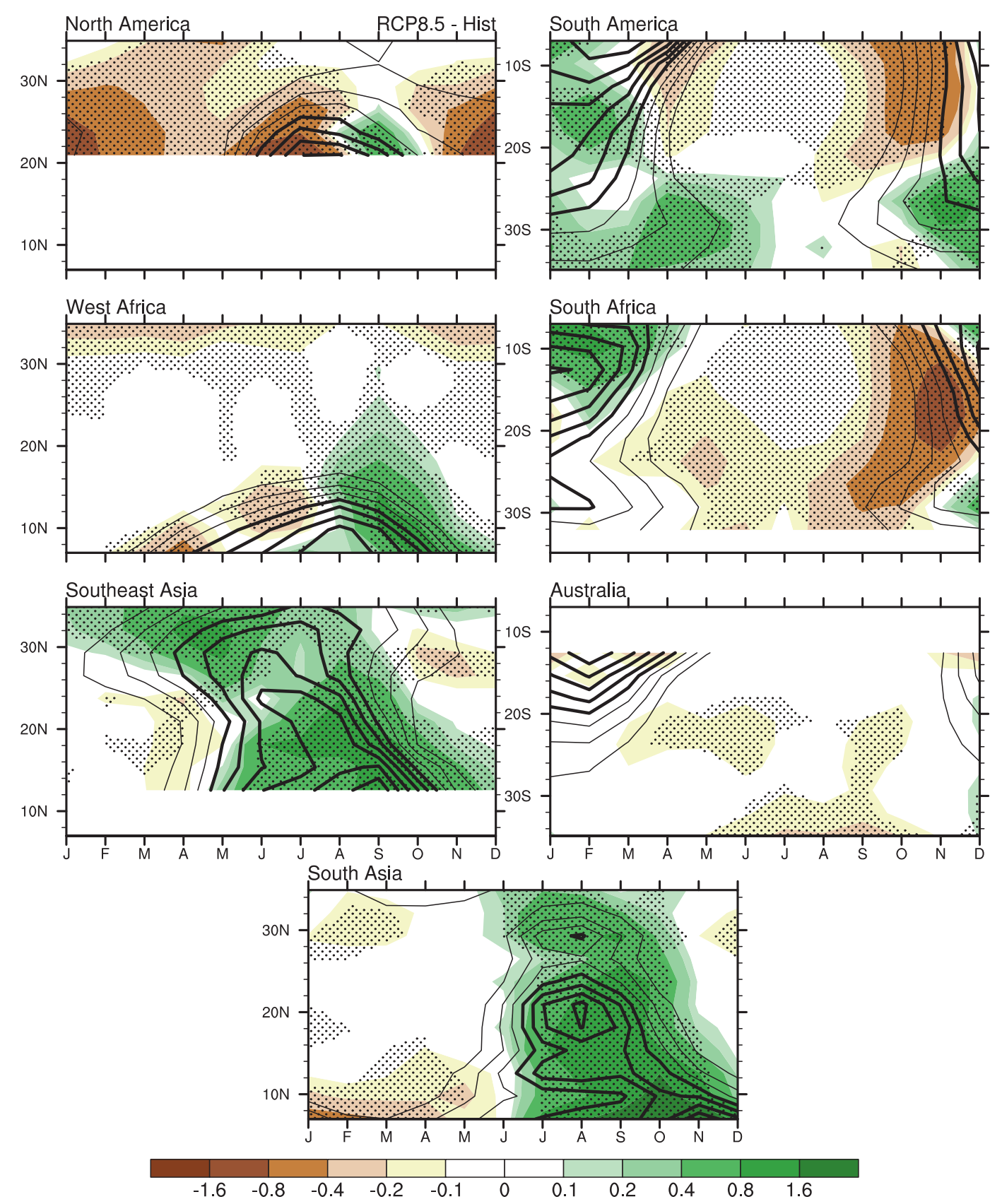

FIG. 5. Zonal mean annual cycles of precipitation $\left(\mathrm{mm} \mathrm{day}^{-1}\right)$, averaged for longitudes for each monsoon region as specified in the text for the 17-model ensemble-mean Hist (black contours) and projected changes, RCP8.5 minus Hist (colors). Climatology and differences are masked for land.

precipitation is masked for land only grid points and the simulated climatology (black contours with thicker lines beginning at $5 \mathrm{~mm} \mathrm{day}^{-1}$ ) shows the poleward extension of precipitation during the warm season (JJA in the Northern and DJF in the Southern Hemisphere). An intensification of the dry season is seen in all of the regional monsoons. Early summer decreases and late summer increases in precipitation are evident in the
American and African monsoon regions in both hemispheres. However, South and Southeast Asia show little change during spring and increases during most of the rainy seasons. Compared with CMIP3 (SRRGC), the CMIP5 results indicate stronger responses in the Americas and Africa (expected towing to the stronger radiative forcing in the RCP8.5 scenario) but a weaker response in Southeast Asia. 

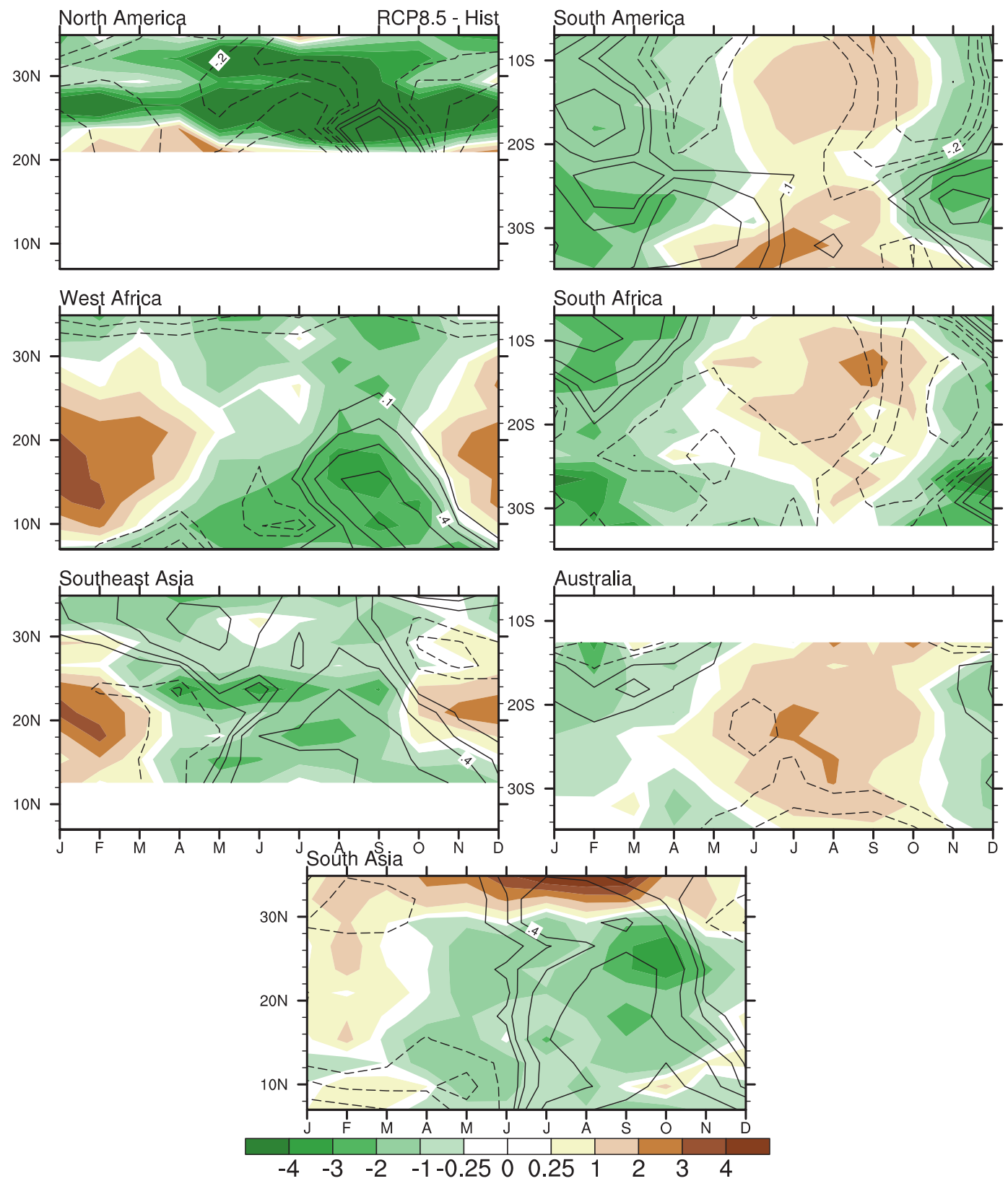

FIG. 6. As in Fig. 5 but for moist static energy vertical difference (VMSE), with precipitation changes $\left(\mathrm{mm} \mathrm{day}^{-1}\right)$ (black contours) for reference.

The remote and local mechanisms are further investigated for each region, using our measure of changes in vertical stability $\nabla$ MSE. Figure 6 shows projected changes in the zonal mean annual cycle of VMSE, with precipitation changes given in millimeters per day (black contours). All monsoon regions exhibit increased vertical stability (remote mechanism) during the dry season and increased instability (local mechanism) during the rainy season. In addition, the spring drying extends beyond the reversal of VMSE to an increased instability in the transition from dry to wet seasons. Previous results showed that, where the precipitation decreases continue beyond the transition to a decreased stability (according to the VMSE measure), the lowlevel increases in MSE were due largely to increases in temperature rather than moisture. This is true for the present results in the American and Southern African monsoons: increases in DSE are large in early summer followed by increases in the moisture term $L q$ just before rainfall increases (not shown). This has been 
affirmed also in the CMIP5 results for North America (Cook and Seager 2013). West Africa is more complicated and both DSE and $L q$ increase in early summer, yet precipitation shows a decrease until late summer. At the end of a more intense dry season, local evaporation is likely to be less important than atmospheric moisture transport into the region. Because the transition from dry to wet seasons depends upon atmospheric moisture transport, our next step is to examine projected changes in the divergence of moisture fluxes.

\section{c. Evaluation of moisture budget}

In monsoon regions, the transition from the dry to the wet season occurs in three phases. First, where surface moisture is available, available potential energy increases locally owing to increasing latent heat fluxes (initiation). Second, a transition in the large-scale circulation leads to net moisture convergence (development). Finally, in the mature onset phase, an upper-tropospheric anticyclonic circulation continues to spin up until it reaches its full strength ( $\mathrm{Li}$ and $\mathrm{Fu}$ 2004). The monsoon can therefore be delayed because of lower latent heat fluxes associated with negative springtime soil moisture anomalies (Collini et al. 2008; Small 2001). Once the rainy season begins, the local land surface influence becomes less important ( $\mathrm{Li}$ and $\mathrm{Fu} 2004$ ), although land wetness anomalies can also influence rainfall during the monsoon season (Taylor et al. 2010; Grimm et al. 2007). To investigate changes in the atmospheric moisture budget, we examine its components-precipitation, moisture flux divergence, and evaporation-all in units of millimeters per day, in the global tropics as well as in the regional monsoons.

Ensemble-mean changes in the global zonal-mean annual cycle of moisture flux divergence are shown in Figs. $7 \mathrm{c}$,d with the precipitation [now in millimeters for comparison with divergence (Figs. 7a,b) and evaporation (Figs. 7e,f)]. The simulated 1981-2005 climatologies (black contours) are also given for each variable and illustrate the model seasonal evolution of moisture in the global monsoon. The tropical rainfall band migrates seasonally, as well as the moisture convergence (dashed lines in Figs. 7c,d), which follows the maximum in solar heating. The global zonal mean evaporation is greater than $3 \mathrm{~mm}^{-1 a y}{ }^{-1}$ with a weak annual cycle. However, over-land evaporation with values greater than $3 \mathrm{~mm}$ day $^{-1}$ is confined to the migrating band of tropical rainfall and convergence, that is, the global monsoon.

Comparing precipitation to moisture divergence changes reveals that globally the projections indicate increased convergence in regions of climatological convergence and increased divergence in regions of climatological divergence, consistent with many earlier results (e.g., Chou and Neelin 2004). Over Southern Hemisphere land areas, increased divergence and decreased evaporation (Figs. $7 \mathrm{~d}, \mathrm{f}$ ) are coincident with spring and early summer (October/November) precipitation decreases (Fig. 7b). Northern Hemisphere changes are less noticeable and not significant in the CMIP5 results.

Figures 8, 9, and 10 show the changes in moisture flux divergence, evaporation, and near-surface relative humidity in the individual monsoon regions, to be compared with precipitation changes in Fig. 5. The simulated climatological values of each variable are given as black contours. In addition, the maps in Figs. 11 and 12 show the early [June (November) in the Northern (Southern) Hemisphere] and late [September (February) in the Northern (Southern) Hemisphere] summer changes in precipitation, moisture flux divergence, and evaporation. Here we discuss each region and follow by summarizing the common responses.

In North America precipitation decreases year-round, except for a short period of projected increase in the late rainy season (September-October). The precipitation decreases (increases) are associated with increases (decreases) in moisture flux divergence, and there is a weaker increase in convergence in April and May that does not yield an increase in rainfall. Evaporation rates are unchanged after the rainy season (August-December), then decrease through July with the largest decrease in April and May. This suggests that a reduction in moisture transport is important for the decrease in early summer precipitation, but decreased local evaporation plays a role throughout the spring and early summer by limiting the increase of boundary layer moisture, which can be seen as decreases in near-surface relative humidity. Indeed, the map views in Figs. 11 and 12 show that in June evaporation plays a dominant role in reducing boundary layer humidity: evaporation is reduced throughout the region, while changes in moisture divergence are positive in the south and negative in the north. Thus, the North American monsoon is characterized by increased surface aridity and requires additional moisture transport to meet an increased need for moisture in a warmer world.

In the West African monsoon, projections indicate a reduction in spring and early summer (May-July) with increased rainfall in late summer (September-November). The precipitation decreases align closely with increases in moisture flux divergence. Evaporation changes are negligible much of the year but do show increases at the end of the rainy season (September-November) and a slight decrease in April and May equatorward of $10^{\circ} \mathrm{N}$. The increased late season rainfall yields increases in near-surface relative humidity (September-November), 

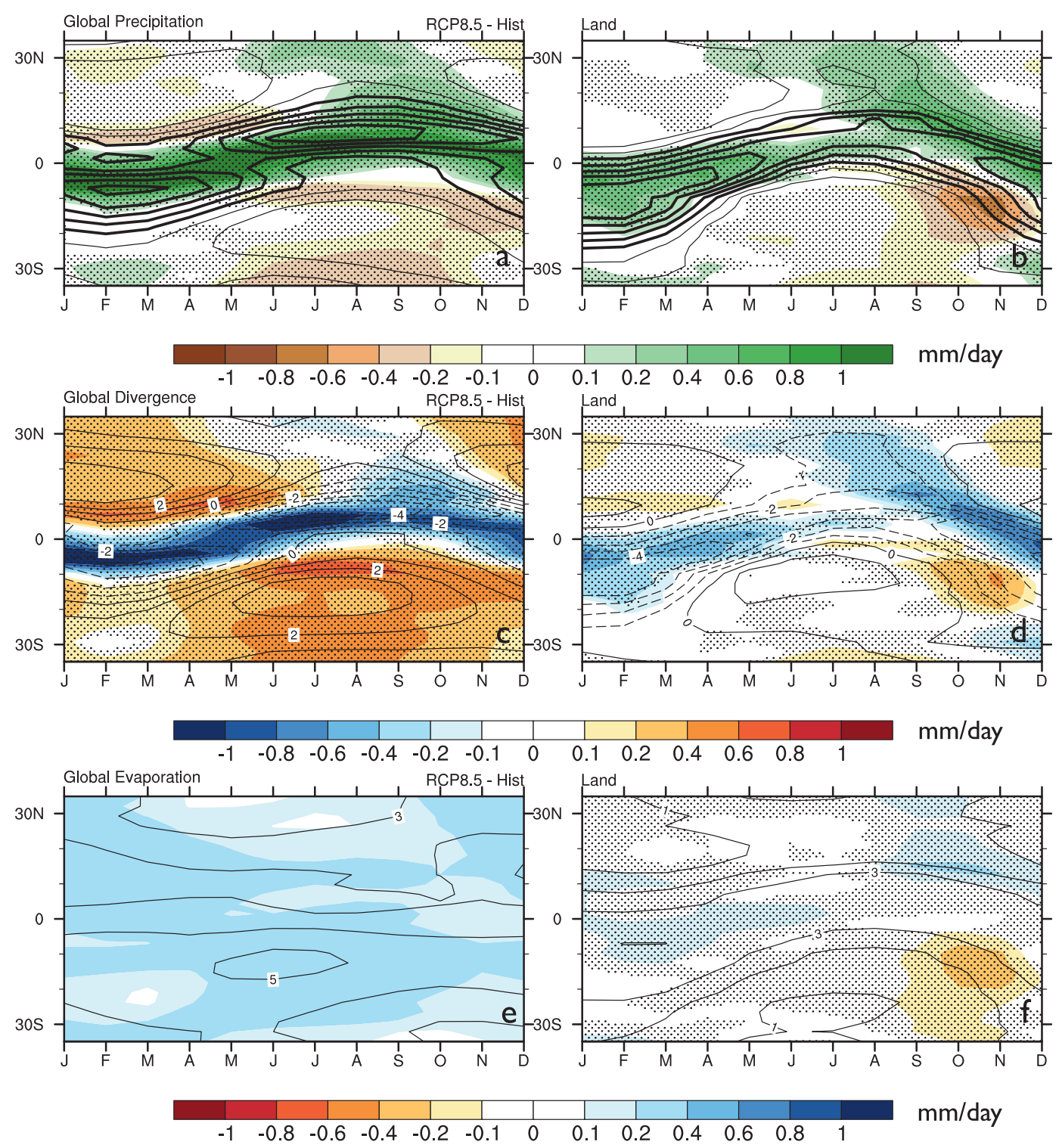

FIG. 7. Zonal mean annual cycles of tropical (a) precipitation, (c) divergence, and (e) evaporation $\left(\mathrm{mm} \mathrm{day}^{-1}\right)$, (left) global and (right) land only, for 17-model ensemble-mean Hist (black contours) and RCP8.5 minus Hist (colors) with simulated Hist climatology (black contours). Stippling indicates significance at the $1 \%$ level, with all areas significant in (e).

which then does not show much change from present until the early rainy season, when decreased convergence results in lower relative humidity. The early season reduction of rainfall in the West African region then appears to result mostly from increased moisture flux divergence, with the local evaporation playing a less important role and despite an earlier switch to less stable conditions given changes in $\mathrm{VMSE}$. The more dominant role of moisture divergence is seen in Fig. 11, whereas Fig. 12 shows the increase in late summer rainfall being associated with increases in both evaporation and moisture convergence.
In South America precipitation decreases are projected in both spring (September-November) and fall (March-April) equatorward of $25^{\circ} \mathrm{S}$. Coincident with these reductions are increases in rainfall between $25^{\circ}$ and $35^{\circ} \mathrm{S}$, which have been shown to result from the poleward expansion of the South Atlantic subtropical anticyclone and the South Atlantic convergence zone (SACZ) (SRRGC). During the peak rainy season (December-February) rainfall increases in the CMIP5 projections. The rainfall decreases are aligned with increases in moisture flux divergence and, in early summer (September-November), also with a maximum decrease 

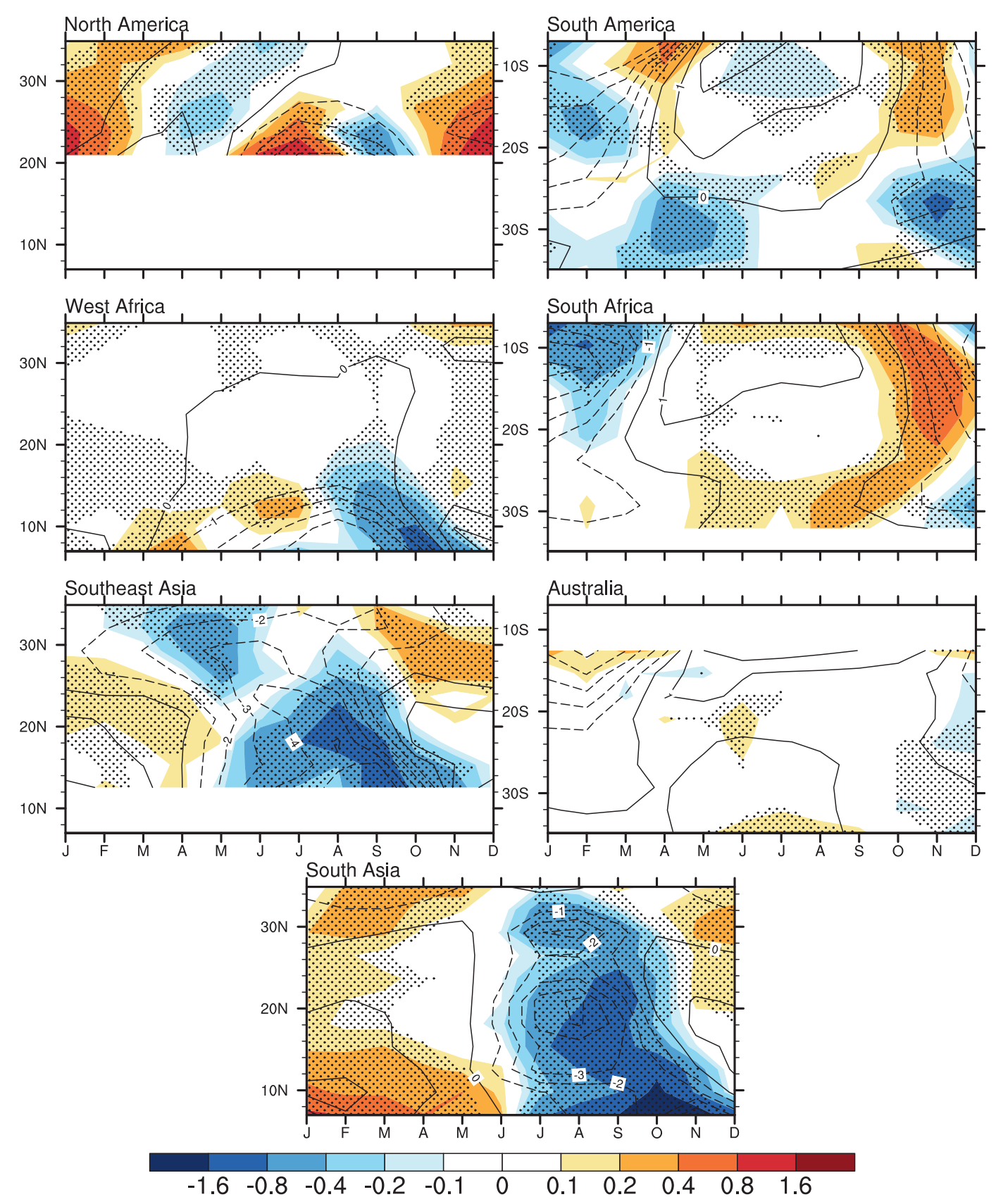

FIG. 8. As in Fig. 5 but for divergence.

in evaporation. Near-surface relative humidity also exhibits a sharp decrease at this time. Figures 11 and 12 are consistent with this picture and further suggest that evaporation and moisture transport changes contribute equally to drying in early summer. In late summer the local mechanism works effectively with increased evaporation and moisture convergence to yield excess rainfall.

The monsoon in Southern Africa responds similarly to that in South America in a number of ways. Precipitation decreases in spring (September-November) and increases in summer (January-March) as a consequence of changes in moisture flux divergence. Here too, reduced evaporation rates in spring (SeptemberNovember) are comparable in magnitude to reduced moisture transport convergence (Fig. 11), which combine to amplify the reduction in boundary layer humidity as seen in the near-surface relative humidity. Thus, the monsoon region in southern Africa is characterized by overall increased surface aridity, with insufficient local moisture at end of dry season, which 

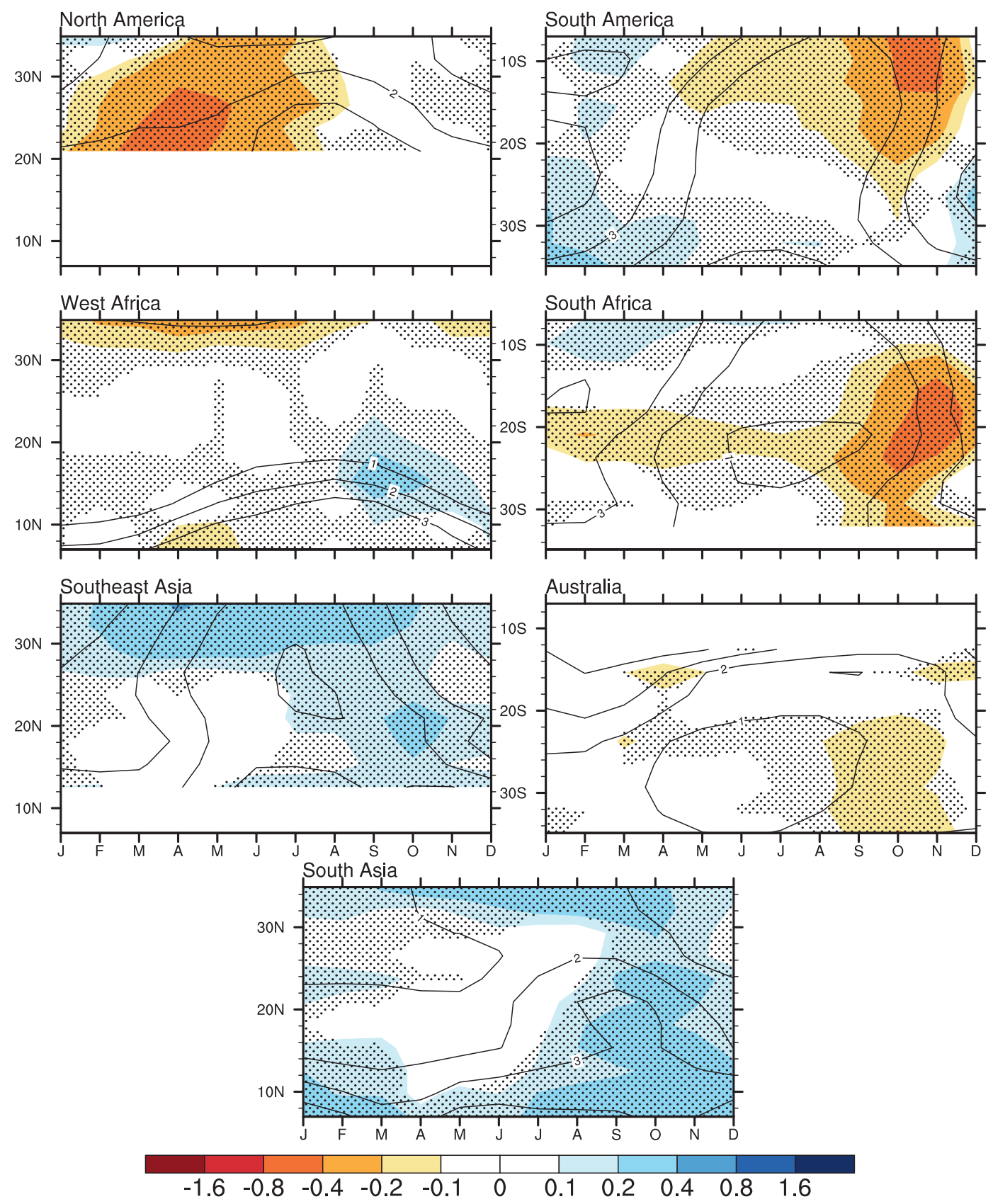

FIG. 9. As in Fig. 5 but for evaporation.

requires moisture transport and additional convergence. Once this requirement is met, increased convergence and rainfall occur (Fig. 12) but do not penetrate poleward of $20^{\circ} \mathrm{S}$, where drier conditions are apparent, with reduced evaporation through the annual cycle.

The annual cycle of rainfall in Southeast Asia shows small precipitation decreases during the dry season into March-April, followed by increases through most of the rainy season (May-November). Rainfall increases can be explained in large part by increases in moisture convergence. However, unlike in the monsoon regions discussed above, in Southeast Asia evaporation increases are seen well after the rainy season (JuneDecember), with no decreases apparent in spring (see also Figs. 11 and 12). While near-surface relative humidity does decrease owing to warmer temperatures, there are no sharp decreases in spring. In this region, then, the local mechanism can operate as usual, without limitations on early season moisture availability. Overall, despite increased divergence in winter, there is ample 

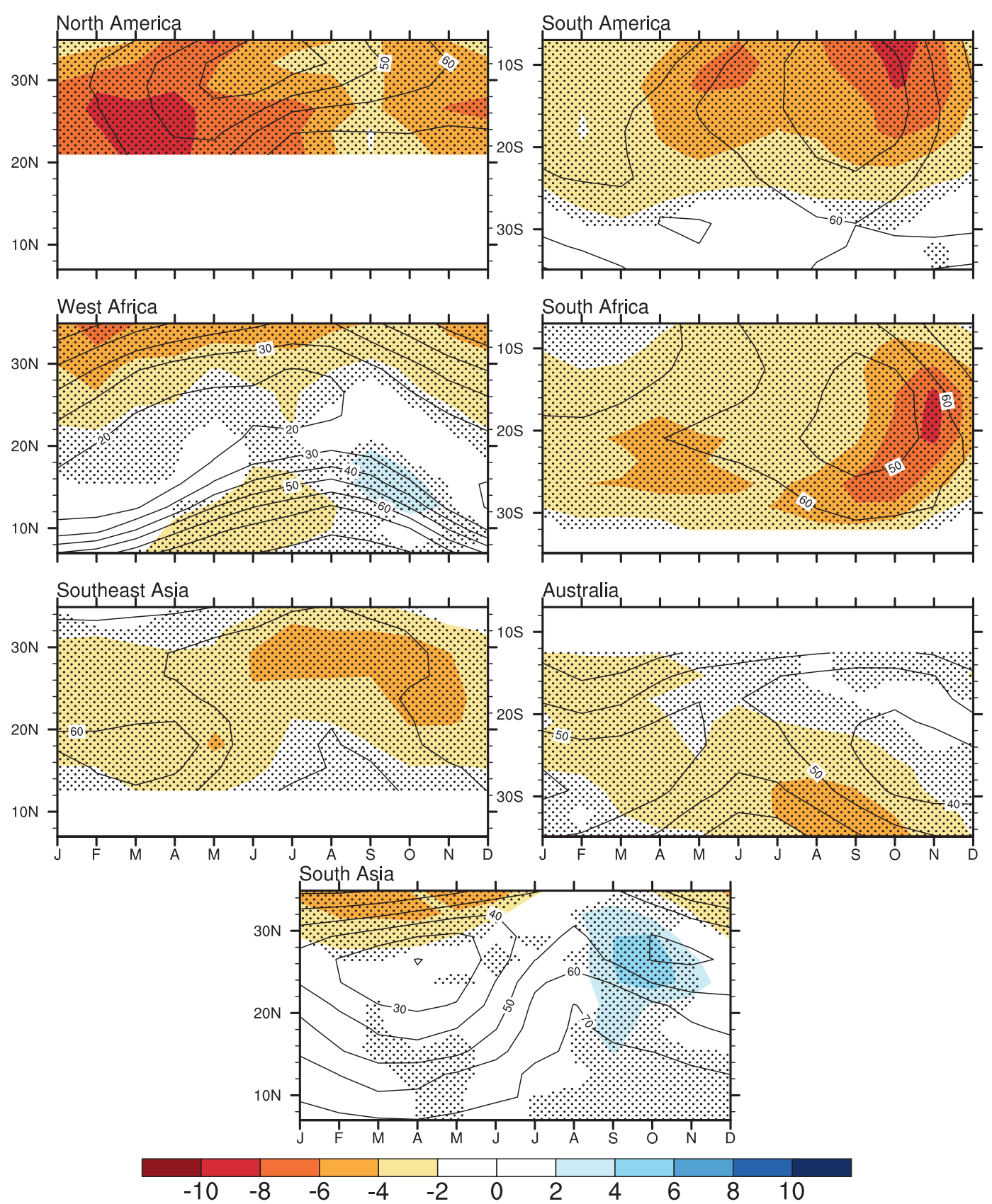

FIG. 10. As in Fig. 5 but for near-surface relative humidity (\%). Note that the ensemble mean for this variable is based on 14 models only, as it was not available for three models (FIO-ESM, GFDL CM3, and MPI-ESM-LR) at the time of writing.

local evaporation to moisten the boundary layer and initiate moisture convergence, which then increases to result in more rainfall because of the thermodynamical increase in atmospheric water vapor.

The South Asian monsoon has similarities to the Southeast Asia monsoon. Although increased divergence is strong during the dry season, precipitation changes are generally small, with only small reduction in rainfall (January-April). Increases in moisture convergence are seen beginning in July and extend through November, which can explain much of the increased rainfall seen during this period. Evaporation rates in the region are higher, especially during the late rainy season and through much of the winter (Fig. 12). The lack of reduction in evaporation during winter and spring (Fig. 11) and no decrease in relative humidity both indicate that 

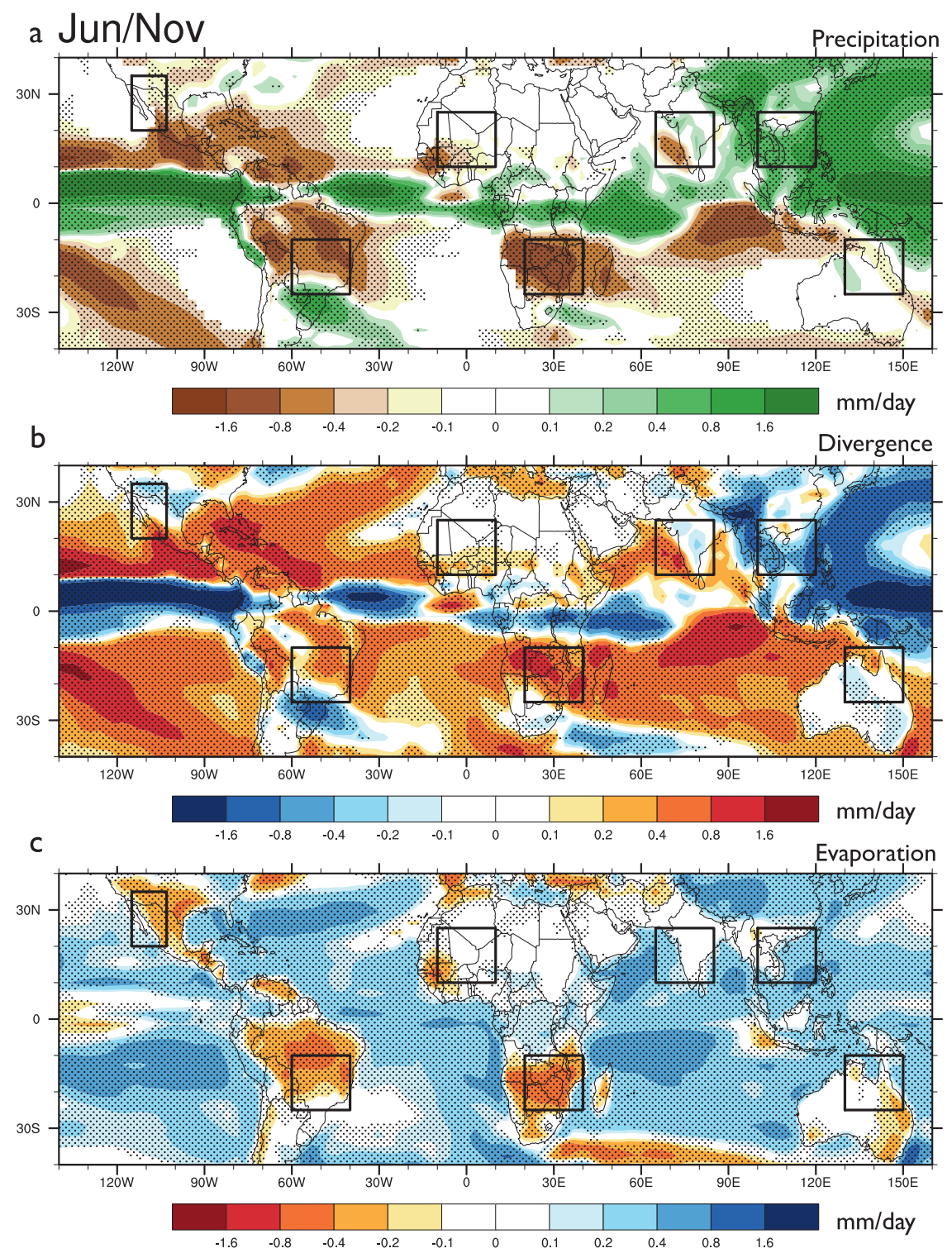

FIG. 11. Early summer, June (November) Northern (Southern Hemisphere) and November (Southern Hemisphere), RCP8.5 minus Hist differences in (a) precipitation, (b) divergence, and (c) evaporation $\left(\mathrm{mm} \mathrm{day}^{-1}\right)$. Boxes specify monsoon regions; stippling indicates significance.

sufficient local moisture is available and with enhanced moisture flux convergence combine to initiate the local mechanism.

The Australian region is remarkable for the lack of overall changes projected in precipitation, moisture divergence, and evaporation, though relative humidity near the surface decreases owing to warming temperatures. This lack of change is in contrast with the increases in rainfall projected from CMIP3 in the Fourth Assessment Report (Meehl et al. 2007) and will be addressed further in the next section.
The four regions that exhibit the springtime drying (American and African monsoons) in the zonal-mean annual cycles suggest that decreases in both moisture convergence and evaporation are responsible for the drying. Although the near-surface relative humidity decreases through much of the year, the largest decreases are seen in spring, coincident with decreases in evaporation and convergence. Over North and South America and Southern Africa, the decreases in early summer evaporation and moisture convergence are similar in magnitude, suggesting that both play an 

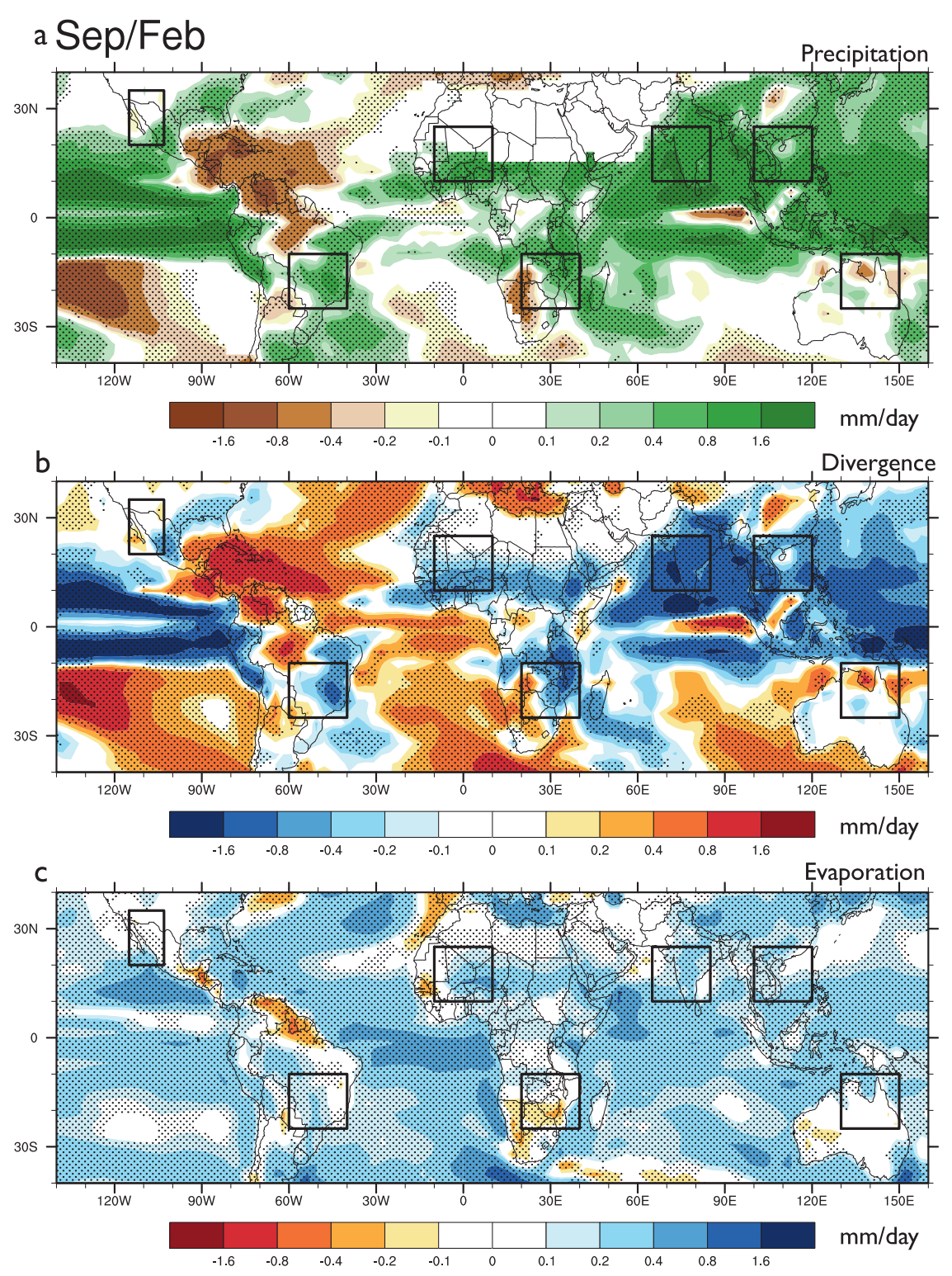

FIG. 12. As in Fig. 11 but for late summer, September/February.

important role in reducing moisture availability for the local mechanism to take effect. Over West Africa increases in moisture divergence may be more important than changes in evaporation. Interestingly, the two regions that do not show spring drying-Southeast Asia and South Asia-do show strong increases in moisture flux convergence, as well as no decreases in evaporation.

The results also suggest an important role for moisture availability during the transition from dry to wet seasons. In the regions where boundary layer (and surface) moisture remains unchanged, moisture convergence increases early in the season and there is no decrease in early season rainfall; yet, for those regions where the boundary layer (and surface) "dries out" during winter, the transition to wet season requires a buildup of boundary layer moisture that relies on increased moisture transport.

\section{Discussion projections: $1 \% \mathrm{CO}_{2}$}

The CMIP5 results thus far suggest that the precipitation annual cycle response of the American and African monsoons is similar to those seen in CMIP3, with a redistribution of rainfall from early to late summer. However, the Southeast Asian monsoon shows a weaker response, that is, less drying in early summer in CMIP5. The global response in the Northern Hemisphere also indicates less drying in early summer, and 
results do not show a stronger response over land in the Northern Hemisphere. Recall that the results of SRRGC indicated a stronger drying response over land than the global mean in both hemispheres. What might cause this difference in the Northern Hemisphere response in the CMIP5 results compared with CMIP3?

The RCP8.5 scenario achieves a higher radiative forcing in the year $2100\left(8.5 \mathrm{~W} \mathrm{~m}^{-2}\right)$ than did the SRES A2 scenario that was analyzed for CMIP3, and for this reason a stronger response overall would be expected, all else being equal. The new scenario also incorporates reductions in several aerosol species (including sulfate aerosols, black carbon, and organic carbon) during the twenty-first century, which yield direct effects on radiation and indirect effects on cloud properties, radiation, and precipitation. In the RCP8.5 scenario aerosol changes are largest over Asia and Africa, more of the models include the complex indirect effects, and these effects can complicate the climatic response regionally (Lamarque et al. 2011; Villarini and Vecchi 2012). The CMIP5 radiative forcing is therefore complicated by "additional factors." The A2 scenario employed in CMIP3 did not include as many aerosol species, and most models included only their direct radiative effects. To simplify and isolate the response to greenhouse gas forcing in the CMIP5 model suite, we examine the $1 \% \mathrm{CO}_{2}$ experiment using the piCont as the control for the 11 models available. Because these idealized experiments include no aerosol forcing, they provide a view of the response to greenhouse gas forcing only. Thus, if the Northern Hemisphere land response is similar to that seen in the CMIP3, there is some basis to state that changes in forcings, more than in model formulations, induce a reduced early season drying in the Northern Hemisphere RCP8.5 scenario.

In Figs. $13 \mathrm{c}-\mathrm{f}$, the global $1 \% \mathrm{CO}_{2}$ minus PiCont precipitation and $\nabla \mathrm{MSE}$ are shown and the RCP8.5 minus Hist results are reproduced for the 11-model subset for direct comparison (Figs. 13a,b). Indeed, the idealized experiments results are similar to CMIP3 with a larger decrease in rainfall over land extending further into summer in the Northern Hemisphere as well as in the Southern Hemisphere. As in CMIP3, the precipitation declines extend beyond the time at which the change in stability, given by $\mathrm{VMSE}$, switches from more to less stable than present day.

The regional monsoon precipitation changes in the idealized CMIP5 experiment are shown in Figs. 14 and 15. The regional responses indicate greater early summer drying in the Southeast Asian and West African regions in this simplified greenhouse gas experiment. At the same time the South Asian monsoon shows increased rainfall earlier (in June rather than July) in the idealized case compared with the RCP8.5 scenario. The overall response in the Northern Hemisphere between $10^{\circ}$ and $20^{\circ} \mathrm{N}$ in May and June is reduced rainfall (Figs. 13c,d), which suggests that the Southeast Asian and African reductions in rainfall are dominating the response at these latitudes.

The reduction of aerosol forcing in the RCP8.5 scenario during the twenty-first century is larger than that employed in CMIP3 with fewer aerosols in 2100, especially over Asia and Africa where they are relatively abundant in present day. According to recent observational and modeling studies, while monsoon precipitation responses to various aerosol species can be complex, the expectation is for an increase in monsoon precipitation given a reduction in aerosol counts (Lamarque et al. 2011; Turner and Annamalai 2012). This is consistent with the finding here that the South Asian monsoon rainfall shows the largest increase in the $1 \% \mathrm{CO}_{2}$ experiment in which there are no aerosols. It is notable that early summer precipitation is reduced in the Southeast Asian and West African monsoons while South Asian rainfall increases in May and June. The opposite is true in the RCP8.5 experiment: South Asian rainfall does not increase in May and June, and the West African and Southeast Asian decreases are smaller.

While the exact causes of the reduced Northern Hemisphere response remain to be identified, the $1 \% \mathrm{CO}_{2}$ experiment results do suggest that monsoon region annual cycle responses are related to greenhouse gas forcing. The redistribution of rainfall from early to late summer in the American and African monsoons is clearly seen in the idealized experiment. The reduction in the Northern Hemisphere response is likely a result of complex effects of additional factors in the RCP8.5 scenario in West Africa, South Asia, and Southeast Asia. In addition, rainfall anomalies in Australia do not conform to the expected pattern of early season decrease and late season increase, a result that stresses how regional and local-scale rainfall changes continue to be uncertain.

\section{Conclusions}

Twenty-first-century projections of precipitation in a number of monsoon regions were plagued by uncertainty due to model disagreement on even the direction of change (Giannini et al. 2008; Turner and Annamalai 2012; Vera et al. 2006). Yet several studies suggested that coherent shifts can be seen within the annual cycle, which are not represented in annual or warm season averages (Biasutti and Sobel 2009; SRRGC). Recent analyses of CMIP5 models have much improved the understanding of monsoon projections and show that the global monsoon is expected to 

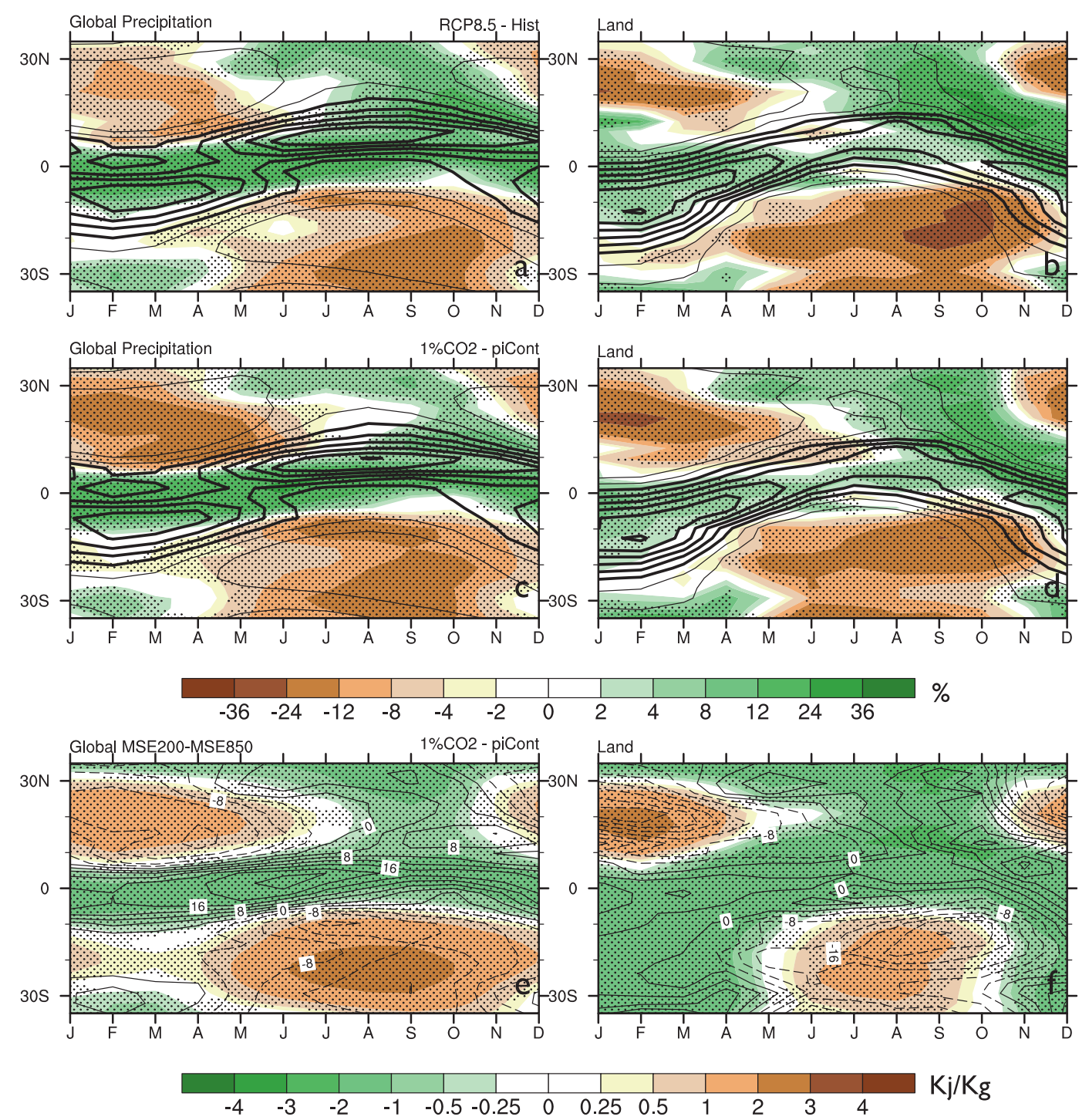

FIG. 13. As in Fig. 4 but for (a),(b) 11 models only and (c)-(f) CMIP5 piCont (black lines) and differences $1 \% \mathrm{CO}_{2}$ minus piCont (colors) for 11 models.

increase in its area, total precipitation, and intensity (Lee and Wang 2012; Hsu et al. 2012, 2013; Kitoh et al. 2013). Still, detailed regional analyses of CMIP5 experiments indicate a redistribution of rainfall within the rainy season in West Africa and North America (Cook and Seager 2013; Biasutti 2013). Our analysis has examined projected changes in the annual cycle of precipitation in monsoon regions, using a moist static energy framework to evaluate competing mechanisms, which have been previously identified as being important in precipitation changes over land.

Two competing mechanisms have been examined, involving the differing responses of simulated precipitation to greenhouse gas forcing: a local mechanism wherein increased downwelling terrestrial radiation increases evaporation, which leads to increased lowlevel moist static energy and decreased stability with consequent increases in precipitation as well as recycling of moisture, and a remote mechanism in which increased SSTs warm the tropical troposphere, increase stability, and decrease precipitation. These are evaluated in time throughout the annual cycle, with an emphasis on the transition from dry to wet seasons. Also examined are relevant terms in the moisture budget (moisture flux divergence and evaporation). The remote (top down) mechanism controls the projected changes during winter, and the local (bottom up) mechanism controls the switch to increased precipitation during summer in most monsoon regions. During the spring/early summer transition from dry to wet conditions, evaporation and 

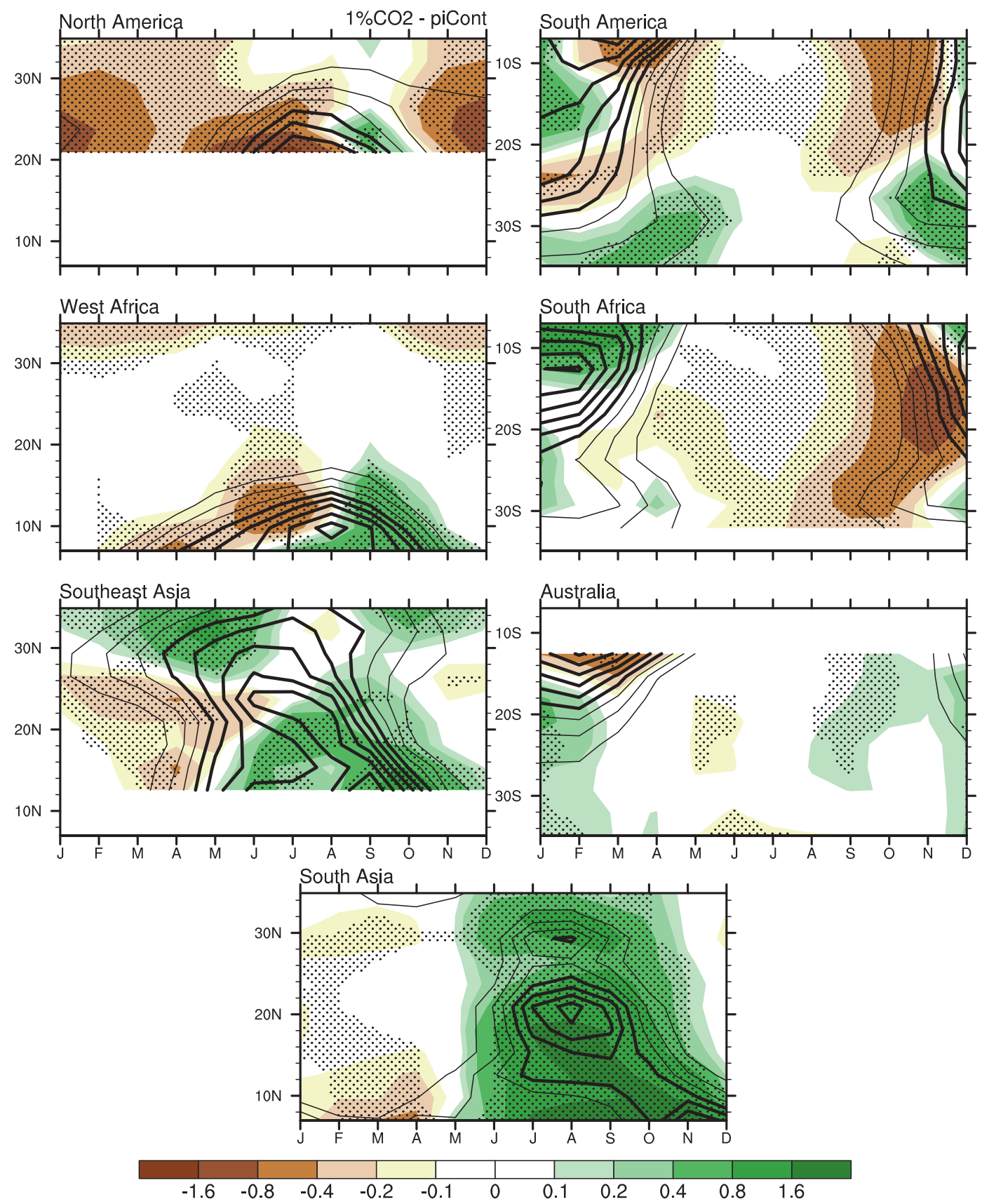

FIG. 14. As in Fig. 5 but for CMIP5 piCont (black lines) and differences $1 \% \mathrm{CO}_{2}$ minus piCont (colors) for 11 models.

moisture flux convergence play critical roles toward the accumulation of boundary layer moisture. Regions where boundary layer moisture availability is reduced owing to decreases in evaporation and moisture convergence experience an enhanced convective barrier during early summer. Alternatively, regions characterized by adequate evaporation and moisture convergence do not experience reductions in early summer precipitation.

Our results indicate an enhanced convective barrier (early summer drying and late summer increase) in rainfall in the American and African monsoons. This response is seen in the individual model results as well as in the ensemble mean and for North America and West Africa have been reaffirmed (Cook and Seager 2013; Biasutti 2013). In South and Southeast Asia, the precipitation changes do not show early summer drying, nor do they indicate decreases in evaporation. This suggests that evaporation can play an important role in the transition season: where moisture is available for evaporation, the local mechanism is activated and together with 

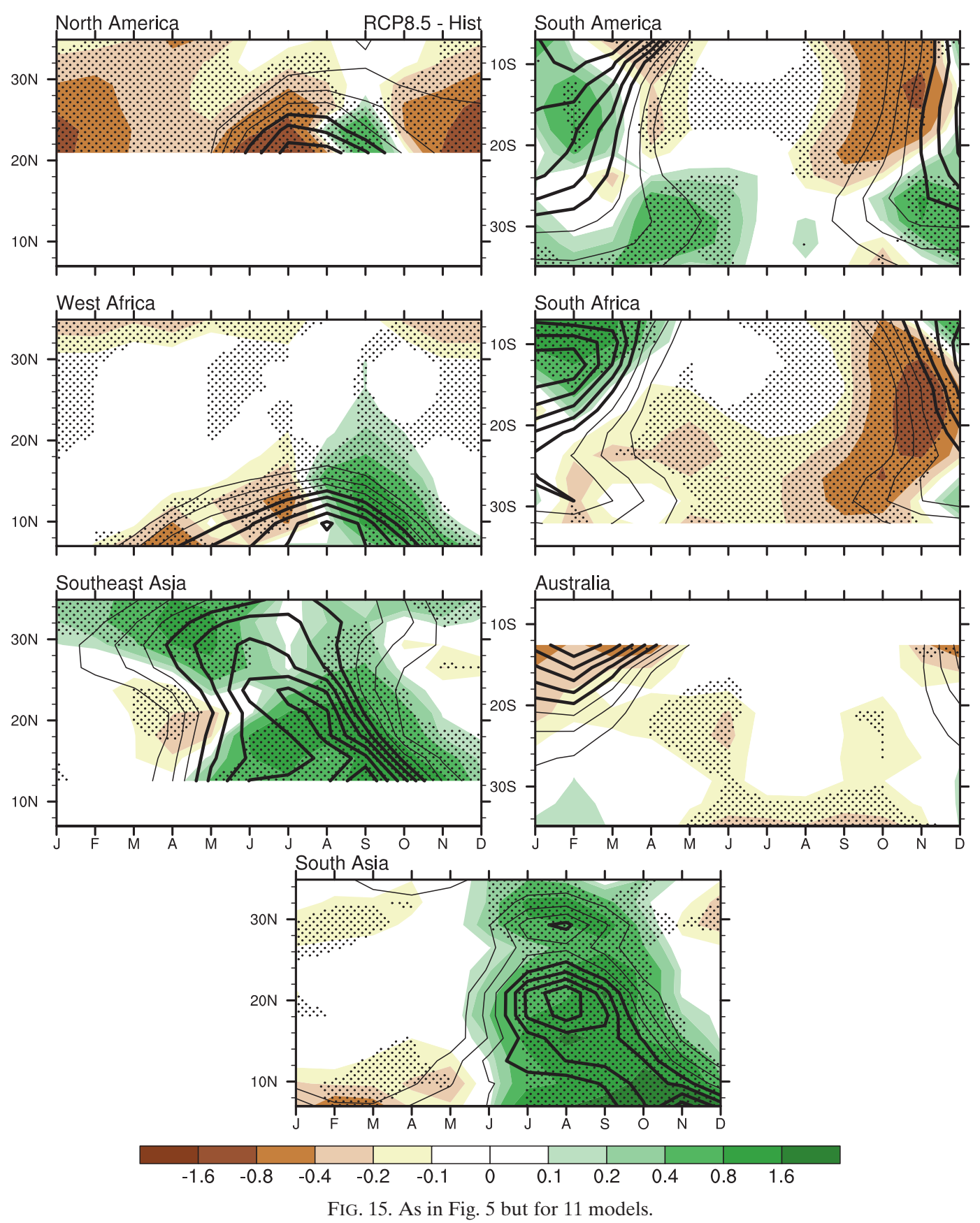

moisture flux convergence yields sufficient early summer rainfall. Where there is inadequate moisture for enhanced longwave radiative forcing to initiate local evaporation, early summer rainfall decreases (e.g., Delworth and Manabe 1989). In all regions, the thermodynamic response to warming that yields increases in atmospheric moisture results in increased transport and convergence in late summer and increases in precipitation (e.g., Fasullo 2012; Lee and Wang 2012; Hsu et al. 2012, 2013).
Analysis of idealized CMIP5 experiments that include only greenhouse gas forcing suggests that reductions in the early summer drying responses in Southeast Asia and West Africa are likely due to additional factors in the RCP8.5 scenario (i.e., the non-greenhouse gas forcings, which include reductions in a number of aerosol species). However, the specific response in these regions to the non-greenhouse gas forcing remains an open question.

A number of caveats must be considered in the interpretation of these results. First, while there is more 
model agreement in these annual cycle changes than in annual or warm season means, it is clear that the models continue to exhibit substantial biases in tropical precipitation and in the annual cycle of rainfall in monsoon regions. In addition, the responses in several monsoon regions have been modified attributed to additional factors in the RCP8.5 scenario compared with CMIP3 SRES A2 results. While these results can help to explain the mechanisms that underlie projected precipitation changes over land-based monsoon regions, the measure of free-tropospheric stability employed here ( $\nabla M S E$ ) cannot fully explain precipitation changes, especially in West Africa where local dynamics (shallow circulation, eddies, horizontal advection, etc.) can result in rainfall decreases even in the presence of less stable conditions (Raymond et al. 2009). Further, the projected changes are clearly embedded in a large-scale response that shows an important component over oceans. Thus, the global drivers of these changes over land may well be oceanic [e.g., amplification of SST annual cycle in the tropics, Dwyer et al. (2012)], and there may also be some influence on the northern margins of the subtropics related to poleward shifts in midlatitude storm tracks (Scheff and Frierson 2012a,b). Finally, because this analysis employs monthly data, the emphasis here has been on early season rainfall and not on delayed onset of the rainy season. Examination of the timing of onset and its changes will require analysis of daily data and should consider interactions between the irrotational and nondivergent flow fields during this critical transition (Krishnamurti and Ramanathan 1982).

Nevertheless, there are important implications of these results. First, our findings are not inconsistent with recent analyses of the global monsoon in CMIP5 projections that indicate increases in global monsoon area, precipitation, and intensity (Lee and Wang 2012; Hsu et al. 2012, 2013; Kitoh et al. 2013), as we show increased late season rainfall as well. However, our results do suggest that use of annual or warm season averages alone will mask the coherent signals shown here in the CMIP5 projected annual cycle of rainfall. Indeed, when transition seasons are included (e.g., Hsu et al. 2013, Fig. 4) the increases in rainfall (for the global monsoon including land and ocean areas) are largest in the late rainy season. Second, the projected changes in the annual cycle of rainfall appear to be a response to greenhouse gas forcing. Third, the role of local evaporation and boundary layer moisture in the land-based monsoon regions is critical in determining the regional transition season response. Fasullo (2012) has also made this argument in an analysis of the global monsoon in the CMIP3 data. Changes in the global monsoon precipitation have been difficult to evaluate in both observations and projections. As described in our results, viewing monsoons from their inherent ties to the annual cycle could help to fingerprint changes as they evolve.

Acknowledgments. We acknowledge the World Climate Research Programme Working Group on Coupled Modelling, which is responsible for CMIP, and we thank the climate modeling groups (listed in Table 1 of this paper) for producing and making available their model output. For CMIP the U.S. Department of Energy Program for Climate Model Diagnosis and Intercomparison provides coordinating support and led development of software infrastructure in partnership with the Global Organization for Earth System Science Portals. This research was funded in part by the Climate Program Office at NOAA Model Analysis and Prediction Program (MAPP) Award NA11OAR4310109. SR acknowledges the support of the DOE through the LANL LDRD program. MB acknowledges NSF Award AGS-0946849.

\section{REFERENCES}

Annamalai, H., K. Hamilton, and K. R. Sperber, 2007: The South Asian summer monsoon and its relationship with ENSO in the IPCC AR4 simulations. J. Climate, 20, 1071-1092.

Biasutti, M., 2013: Forced Sahel rainfall trends in the CMIP5 archive. J. Geophys. Res. Atmos., 118, 1613-1623, doi:10.1002/jgrd.50206.

— seasonal cycle in a warmer climate. Geophys. Res. Lett., 36, L23707, doi:10.1029/2009GL041303.

$\longrightarrow, \ldots$, and S. J. Camargo, 2009: The role of the Sahara low in summertime Sahel rainfall variability and change in the CMIP3 models. J. Climate, 22, 5755-5771.

Chiang, J. C., and A. H. Sobel, 2002: Tropical tropospheric temperature variations caused by ENSO and their influence on the remote tropical climate. J. Climate, 15, 2616-2631.

Chou, C., and J. D. Neelin, 2004: Mechanisms of global warming impacts on regional tropical precipitation. J. Climate, 17, 2688-2701.

$\longrightarrow,-$, and H. Su, 2001: Ocean-atmosphere-land feedbacks in an idealized monsoon. Quart. J. Roy. Meteor. Soc., 127, 18691891.

Christensen, J. H., and Coauthors, 2007: Regional climate projections. Climate Change 2007: The Physical Science Basis, S. Solomon et al., Eds., Cambridge University Press, 847940.

Collini, E. A., E. H. Berbery, V. R. Barros, and M. E. Pyle, 2008: How does soil moisture influence the early stages of the South American monsoon? J. Climate, 21, 195-213.

Cook, B. I., and R. Seager, 2013: The response of the North American monsoon to increased greenhouse gas forcing. J. Geophys. Res., 118, 1690-1699, doi:10.1002/jgrd.50111.

Delworth, T. L., and S. Manabe, 1988: The influence of potential evaporation on the variabilities of simulated soil wetness and climate. J. Climate, 1, 523-547.

_ and - 1989: The influence of soil wetness on near-surface atmospheric variability. J. Climate, 2, 1447-1462. 
Dirmeyer, P. A., Y. Jin, B. Singh, and X. Yan, 2013: Trends in landatmosphere interactions from CMIP5 simulations. J. Hydrometeor., 14, 829-849.

Douville, H., J.-F. Royer, J. Polcher, P. Cox, N. Gedney, D. B. Stephenson, and P. J. Valdes, 2000: Impact of $\mathrm{CO}_{2}$ doubling on the Asian summer monsoon: Robust versus model-dependent responses. J. Meteor. Soc. Japan, 78, 421-439.

Dwyer, J. G., M. Biasutti, and A. H. Sobel, 2012: Projected changes in the seasonal cycle of surface temperature. J. Climate, 25, 6359-6374.

Fasullo, J., 2012: A mechanism for land-ocean contrasts in global monsoon trends in a warming climate. Climate Dyn., 39, 11371147, doi:10.1007/s00382-011-1270-3.

Gedney, N., and P. M. Cox, 2003: The sensitivity of global climate model simulations to the representation of soil moisture heterogeneity. J. Hydrometeor., 4, 1265-1275.

Giannini, A., 2010: Mechanisms of climate change in the semiarid African Sahel: The local view. J. Climate, 23, 743 756.

—- M. Biasutti, I. Held, and A. Sobel, 2008: A global perspective on African climate. Climatic Change, 90,359-383, doi:10.1007/ s10584-008-9396-y.

Grimm, A. M., J. S. Pal, and F. Giorgi, 2007: Connection between spring conditions and peak summer monsoon rainfall in South America: Role of soil moisture, surface temperature, and topography in eastern Brazil. J. Climate, 20, 5929-5945.

Held, I. M., and B. J. Soden, 2006: Robust responses of the hydrological cycle to global warming. J. Climate, 19, 56865699.

Hsu, P.-C., T. Li, J.-J. Luo, H. Murakami, A. Kitoh, and M. Zhao, 2012: Increase of global monsoon area and precipitation under global warming: A robust signal? Geophys. Res. Lett., 39, L06701, doi:10.1029/2012GL051037.

,,-- H. Murakami, and A. Kitoh, 2013: Future change of the global monsoon revealed from 19 CMIP5 models. J. Geophys. Res. Atmos., 118, 1247-1260, doi:10.1002/jgrd.50145.

Kitoh, A., H. Endo, K. Krishna Kumar, I. F. A. Cavalcanti, P. Goswami, and T. Zhou, 2013: Monsoons in a changing world: a regional perspective in a global context. J. Geophys. Res. Atmos., 118, 3053-3065, doi:10.1002/jgrd.50258.

Krishnamurti, T. N., and Y. Ramanathan, 1982: Sensitivity of the monsoon onset to differential heating. J. Atmos. Sci., 39, 12901306.

Lamarque, J.-F., G. Kyle, M. Meinshausen, K. Riahi, S. Smith, D. van Vuuren, A. Conley, and F. Vitt, 2011: Global and regional evolution of short-lived radiatively-active gases and aerosols in the representative concentration pathways. Climatic Change, 109, 191-212, doi:10.1007/s10584-011-0155-0.

Lau, K., M. Kim, and K. Kim, 2006: Asian summer monsoon anomalies induced by aerosol direct forcing: The role of the Tibetan Plateau. Climate Dyn., 26, 855-864, doi:10.1007/ s00382-006-0114-z.

Lawrence, D. M., K. W. Oleson, M. G. Flanner, C. G. Fletcher, P. J. Lawrence, S. Levis, S. C. Swenson, and G. B. Bonan, 2011: The CCSM4 land simulation, 1850-2005: Assessment of surface climate and new capabilities. J. Climate, 25, 2240-2260.

Lee, J.-Y., and B. Wang, 2012: Future change of global monsoon in the CMIP5. Climate Dyn., doi:10.1007/s00382-012-1564-0, in press.

Li, W., and R. Fu, 2004: Transition of the large-scale atmospheric and land surface conditions from the dry to the wet season over Amazonia as diagnosed by the ECMWF Re-Analysis. J. Climate, 17, 2637-2651.
Meehl, G. A., and Coauthors, 2007: Global climate projections. Climate Change 2007: The Physical Science Basis, S. Solomon et al., Eds., Cambridge University Press, 747-845.

_ J. M. Arblaster, and W. D. Collins, 2008: Effects of black carbon aerosols on the Indian monsoon. J. Climate, 21, 2869-2882.

Neelin, J. D., and I. M. Held, 1987: Modeling tropical convergence based on the moist static energy budget. Mon. Wea. Rev., 115, 3-12.

- C. Chou, and H. Su, 2003: Tropical drought regions in global warming and El Niño teleconnections. Geophys. Res. Lett., 30, 2275, doi:10.1029/2003GL018625.

Oki, T., T. Nishimura, and P. Dirmeyer, 1999: Assessment of annual runoff from land surface models using total runoff integrating pathways (TRIP). J. Meteor. Soc. Japan, 77, 235-255

Oleson, K. W., and Coauthors, 2008: Improvements to the community land model and their impact on the hydrological cycle J. Geophys. Res., 113, G01021, doi:10.1029/2007JG000563.

Raymond, D. J., S. L. Sessions, A. H. Sobel, and Ž. Fuchs, 2009: The mechanics of gross moist stability. J. Adv. Model Earth Syst., 1, doi:10.3894/JAMES.2009.1.9.

Rogelj, J., M. Meinshausen, and R. Knutti, 2012: Global warming under old and new scenarios using IPCC climate sensitivity range estimates. Nat. Climate Change, 2, 248-253, doi:10.1038/ nclimate1385.

Scheff, J., and D. Frierson, 2012a: Twenty-first-century multimodel subtropical precipitation declines are mostly midlatitude shifts. J. Climate, 25, 4330-4347.

- and $-2012 \mathrm{~b}$ : Robust future precipitation declines in CMIP5 largely reflect the poleward expansion of model subtropical dry zones. Geophys. Res. Lett., 39, L18704, doi:10.1029/2012GL052910.

Seager, R., and Coauthors, 2007: Model projections of an imminent transition to a more arid climate in southwestern North America. Science, 316, 1181-1184

Seth, A., M. Rojas, and S. A. Rauscher, 2009: CMIP3 projected changes in the annual cycle of the South American monsoon. Climatic Change, 98, 331-357, doi:10.1007/s10584-009-9736-6.

_ S. A. Rauscher, M. Rojas, A. Giannini, and S. J. Camargo, 2011: Enhanced spring convective barrier for monsoons in a warmer world? Climatic Change, 104, 403-414, doi:10.1007/ s10584-010-9973-8.

Small, E. E., 2001: The influence of soil moisture anomalies on variability of the North American monsoon system. Geophys. Res. Lett., 28, 139-142.

Sobel, A. H., and S. J. Camargo, 2010: Projected future seasonal changes in tropical summer climate. J. Climate, 24, 473-487.

- I. M. Held, and C. S. Bretherton, 2002: The ENSO signal in tropical tropospheric temperature. J. Climate, 15, 2702-2706.

Sutton, R. T., B. Dong, and J. M. Gregory, 2007: Land/sea warming ratio in response to climate change: IPCC AR4 model results and comparison with observations. Geophys. Res. Lett., 34 L02701, doi:10.1029/2006GL028164.

Tan, P.-H., C. Chou, and J.-Y. Tu, 2008: Mechanisms of global warming impacts on robustness of tropical precipitation asymmetry. J. Climate, 21, 5585-5602.

Tanaka, H. L., N. Ishizaki, and D. Nohara, 2005: Intercomparison of the intensities and trends of Hadley, Walker and monsoon circulations in the global warming projections. SOLA, 1, 77-80.

Taylor, C. M., P. P. Harris, and D. J. Parker, 2010: Impact of soil moisture on the development of a Sahelian mesoscale convective system: A case-study from the AMMA Special Observing Period. Quart. J. Roy. Meteor. Soc., 136, 456-470, doi:10.1002/qj.465. 
Taylor, K. E., R. J. Stouffer, and G. A. Meehl, 2012: An overview of CMIP5 and the experiment design. Bull. Amer. Meteor. Soc., 93, 485-498.

Trenberth, K. E., D. P. Stepaniak, and J. M. Caron, 2000: The global monsoon as seen through the divergent atmospheric circulation. J. Climate, 13, 3969-3993.

Turner, A. G., and H. Annamalai, 2012: Climate change and the South Asian summer monsoon. Nat. Climate Change, 2, $587-$ 595, doi:10.1038/nclimate1495.

van Vuuren, D. P., and Coauthors, 2011: The representative concentration pathways: An overview. Climatic Change, 109, 5 31, doi:10.1007/s10584-011-0148-z.

Vecchi, G. A., and B. J. Soden, 2007: Global warming and the weakening of the tropical circulation. J. Climate, 20, 43164340 .
Vera, C., G. Silvestri, B. Liebmann, and P. Gonzalez, 2006: Climate change scenarios for seasonal precipitation in South America from IPCC-AR4 models. Geophys. Res. Lett., 33, L13707, doi:10.1029/2006GL025759.

Villarini, G., and G. A. Vecchi, 2012: Twenty-first-century projections of North Atlantic tropical storms from CMIP5 models. Nat. Climate Change, 2, 604-607, doi:10.1038/ nclimate1530.

Wang, B., J. Liu, H.-J. Kim, P. J. Webster, and S.-Y. Yim, 2012: Recent change of the global monsoon precipitation (1979-2008). Climate Dyn., 39, 1123-1135, doi:10.1007/ s00382-011-1266-z.

Xie, P., and P. Arkin, 1996: Analysis of global monthly precipitation using gauge observation, satellite estimates, and numerical model predictions. J. Climate, 9, 840-858. 